Policy Research Working Paper 3026

\title{
Strategic Approaches to Science and Technology in Development
}

\author{
Robert Watson \\ Michael Crawford \\ Sara Farley
}

The World Bank

Human Development Network

Education Team

and

Environmentally and Socially Sustainable Development Vice Presidency

April 2003 


\begin{abstract}
Watson, Crawford, and Farley examine the ways in which science and technology (S\&T) support poverty alleviation and economic development and how these themes have been given emphasis or short shrift in various areas of the World Bank's work. Central to their thesis is the now well-established argument that development will increasingly depend on a country's ability to understand, interpret, select, adapt, use, transmit, diffuse, produce, and commercialıze scientific and technological knowledge in ways appropriate to its culture, aspirations, and level of development. The authors go beyond this tenet, analyzing the importance of S\&T for development within specific sectors. They present policy options for enhancing the effectiveness of S\&T systems in developing countries, review previous experience of the World Bank and other donors in supporting $S \& T$, and suggest changes that the World Bank and its partners can adopt to increase the impact of the work currently undertaken in S\&T. The authors' main messages are:
\end{abstract}

- S\&T has always been important for development, but the unprecedented pace of advancement of scientific knowledge is rapidly creating new opportunities for and threats to development.

- Most developıng countries are largely unprepared to deal with the changes that $S \& T$ advancement will bring.

- The World Bank's numerous actions in various domains of S\&T could be more effective in producing the needed capacity improvements in client countries.

- The World Bank could have a greater impact if it paid increased attention to S\&T in education, health, rural development, private sector development, and the environment.

The strategy emphasizes four S\&T policy areas: education and human resources development, the private sector, the public sector, and information communications technologies.

This paper-a joint product of the Education Team, Human Development Network, and the Environmentally and Socially Sustainable Development Vice Presidency -is part of a larger effort in the Bank to engage client countries in an active science and technology dialogue while increasing awareness of the centralıty of these issues to the Bank's work. Copies of the paper are avallable free from the World Bank, $1818 \mathrm{H}$ Street NW, Washington, DC 20433. Please contact Robert Watson, room MC4-139, telephone 202-473-6965, fax 202-522-7122, emall address rwatson@worldbank.org. Policy Research Workıng Papers are also posted on the Web at http://econ.worldbank.org. The other authors may be contacted at mcrawford@worldbank.org or sfarley@worldbank.org. Aprıl 2003. (52 pages)

The Policy Research Working Paper Senes dissemmates the findings of work in progress to encourage the exchange of ideas about development issues An objective of the sertes is to get the findings out quickly, even if the presentations are less than fully polished. The papers carry the names of the authors and should be cited accordingly. The findings, interpretations, and conclusions expressed in this paper are entirely those of the authors. They do not necessartly represent the view of the World Bank, its Executive Durectors, or the countries they represent 


\section{STRATEGIC APPROACHES TO SCIENCE AND TECHNOLOGY IN DEVELOPMENT}

Robert Watson, Michael Crawford and Sara Farley 



\section{Table of Contents}

Executive Summary Introduction Section A

Section B

Section C

Section D
The Importance of S\&T for

Development.

The Role of S\&T in Poverty Alleviation

The Role of $S \& T$ in Creating Economic Opportunity

Existing S\&T Capacity in the Developing World

Policy Options for Reaping the Benefits

from S\&T

Policies for Building and Maintaining Adequate Human Capital for $S \& T$

Policies that Encourage a Demand for Knowledge in the Private Sector

Policies for Effective Public Support of Scientific and Technological Research

Policies that Maximize the Benefits from Information and Communications

Technologies

Adjusting Policies to Fit the Needs of Smaller, Poorer States

World Bank Experience

in Promoting S\&T Capacity.

- World Bank experience in promoting human capital in S\&T

- World Bank experience in creating demand for knowledge in the productive sector

- World Bank experience in fostering the proper public role for ${ }^{\prime} S \& T$

- World Bank experience with the promotion of ICT infrastructure

Experience of Bi-Lateral Donors, NGOs and Foundations
Rethinking the World Bank's Approach to

Science and Technology in Development

- Increasing awareness

- Increasing attention to S\&T in the four policy areas

- Building the analytical base and promoting global public goods for S\&T

- Strengthening partnerships v-ix

1-5

5-12

12-19

19-26

26-32

33

34-37

38-44

45-52 


\section{RRSOURCES AND ACKNOWLEDGEMIENTS}

This paper on Strategic Approaches to Science and Technology in Development was produced in tandem with several background pieces, including a larger volume, together referred to as "A Resource Book for S\&T in Development." The various background papers composing the resource book treat many of the issues discussed in this strategic approaches paper in greater detail. Throughout this paper, footnotes will direct the interested reader to the more detailed discussions contained in these background papers. Full citations for publications cited in both the strategic approaches paper and the resource book may be found in the bibliography. Titles of the background papers included in the resource book include: "Bi-laterals, NGOs, and Foundation Experience"; "Science and Technology for Development Regional Issues in S\&T Policies for Developing Countries: Africa--Selected Case Studies of S\&T and Innovation Capacity"; "Lessons Learned from Previous Attempts to Promote S\&T Capacity"; "RAND Study: Science and Technology Collaboration-Bulding Capacity in Developing Countries"; "The Millennium Science Initiative"; and, "The Role of the Private Sector in Facilitating the Acquisition of Technology in Developing Countries." Please contact authors Sara Farley or Robert Watson for further inquiries. ${ }^{1}$

This first volume was presented to the Bank Board in tandem with the Tertiary Education Strategy on July 23, 2002, where it received approval and commentary.

The authors would like to thank several kind contributors and reviewers for their 1deas, commentary, edit and support. These individuals include: E1ju Pehu, Lauritz Holm-Nielsen, Gary Alex, Jean-Eric Aubert, Derek Byerlee, Shawki Barghout1, Leonid Norsworthy, Jacob Bregman, Donald Bundy, Charles Kenney, Sarwat Hussain, Mariam Claeson, and Kabır Kumar. Special thanks are due to several external contributors including C.N. R. Rao, Victor Ngu, Caroline Wagner, Gerald Lalor, Attia Sashour, Enk Thulstrup, Naj1a Ariguib, Tony Marjoram, Lill-Ann Bjaarstad Medina, Abed Peerally, Pedro Aymonino, E.M. Essien, Karin Roggenbuck, Jon Andri Lys and M. Shamsher Ali. The team initiated the work under Ian Johnson, vice president of the Environmentally and Socially Sustainable Development Network and finalized the work under Ruth Kagia, director of the Education Department and Jo Ritzen, vice president of the Human Development Network.

Extensive consultations on various drafts were carried out within and outside of the World Bank. In addition to review meetings with various sector staff in the Human Development and Environmentally and Socially Sustainable Development Networks as well as other areas of relevance to the Bank's S\&T work, stakeholder consultations were convened in Paris, Abidjan, and New Delhi to seek the views of the international S\&T community. The list of those who attended these consultations and review meetings and who generously offered written comments would be to long to permit recognition of the contributions of each individual. Annex 3 contains the names, titles and country of origin of all of those individuals who served as reviewers, consultants and peer editors to whom we offer our thanks.

\footnotetext{
I Email addresses follow: rwatson@worldbank.org and sfarley@worldbank.org
} 


\section{List of Acronyms}

\begin{tabular}{|c|c|}
\hline CGIAR & Consultative Group on International Agnicultural Research \\
\hline DALY & Disability-Adjusted Life Years \\
\hline DANIDA & Danish Ministry of Foreign Affaurs \\
\hline DGF & Development Grant Facility \\
\hline DGIS & Dutch Ministry of Foreign Affairs \\
\hline ENRECA & Enhancing Research Capacity (Research Program of DANIDA) \\
\hline $\mathrm{ERC}$ & Engineering Research Centers \\
\hline ESSD & Environmentally and Socially Sustainable Development \\
\hline FDI & Foreign Direct Investment \\
\hline FY & Fiscal Year \\
\hline GDP & Gross Domestic Product \\
\hline GM & Genetically Modified \\
\hline GTOE & Thousand Millın Tons of Oil Equivalent \\
\hline HDN & Human Development Network \\
\hline IARC & International Agricultural Research Centers \\
\hline ICSU & International Counc1l for Scientific Unions \\
\hline ICT & Informatión Communications Technology \\
\hline IFS & Internationál Foundation for Sçience \\
\hline InfoDEV & Information for Development Program \\
\hline IPCC & Intergovernmental Panel on Climate Change \\
\hline IPR & Intellectual Property Rights \\
\hline ISR & Industry-Science Relations \\
\hline ITD & Industrial Technology Development \\
\hline JICA & Japan International Cooperation Agency \\
\hline MDG & Millennium Development Goals \\
\hline MFP & Multi-Factor Productıvity \\
\hline MSB & Mauritius Standards Bureau \\
\hline MSI & Millennium Science Initiative \\
\hline MSTQ & Metrology, Standards, Testing and Quality \\
\hline NARIS & National Agricultural Research Institutes \\
\hline NARS & National Agricultural Research System \\
\hline NGO & Non-governmental Organization \\
\hline NIS & National Innovation System \\
\hline NORAD & Norwegian Agency for Development Cooperation \\
\hline ODA & Official Development Assistance \\
\hline OECD & Organization for Economic Cooperation and Development \\
\hline OED & Operations Evaluation Department \\
\hline PISA & Program for International Student Assessment \\
\hline R\&D & Research and Development \\
\hline$S \& \mathrm{~T}$ & Science and technology \\
\hline SAREC & Department for Research Cooperation of SIDA \\
\hline SIDA & The Swedish International Development Cooperation Agency \\
\hline SME & Small and Medium Enterprises \\
\hline SPAAR & Special Program for African Agricultural Research \\
\hline TDS & Technology Diffusion Scheme \\
\hline TIMSS & Trends International Mathematıcs and Science Study \\
\hline $\mathrm{TSC}$ & Technology Strategy for Competitiveness \\
\hline TWAS & Third World Academy of Sciences \\
\hline UNAIDS & Joint United Nations Program on HIV/AIDS \\
\hline WBI & World Bank Institute \\
\hline
\end{tabular}


This paper examines the ways in which science and technology (S\&T) support poverty alleviation and economic development and how these themes have been given emphasis or short shrift in various areas of the World Bank's work. Central to the paper's thesis is the now well-established argument that development will increasingly depend on a country's ability to understand, interpret, select, adapt, use, transmit, diffuse, produce and commercialize scientific and technological knowledge in ways appropriate to its culture, aspirations and level of development. The paper goes beyond this tenet, analyzing the importance of S\&T for development within specific sectors. It presents policy options for enhancing the effectiveness of S\&T systems in developing countries, reviews the previous experience of the World Bank and other donors in supporting S\&T, and suggests changes that the World Bank and its partners can adopt to increase the impact of the work currently undertaken in S\&T. Its main messages are that: (i) S\&T has always been important for development, but the unprecedented pace of advancement of scientific knowledge is rapidly creating new opportunities for and threats to development; (ii) most developing countries are largely unprepared to deal with the changes that S\&T advancement will bring; (iii) the World Bank's numerous actions in various domains of $S \& T$ could be more effective in producing the needed capacity improvements in client countries; and (iv) the World Bank could have a greater impact if it paid increased attention to S\&T in education, health, rural development, private sector development, and the environment. The strategy emphasizes four S\&T policy areas: education and human resources development, the private sector, the public sector and information communications technologies. 


\section{STRATEGIC APPROACHES TO S\&T IN DEVELOPMENT: EXECUTIVE SUMMARY}

Since its founding, the World Bank has sought to promote specific aspects of science and technology (S\&T), especially in the area of agricultural research. This Strategic Approaches Paper underscores the ways in which science and technology support poverty alleviation and economic development, and explores how to improve the effectıveness of the Bank's role in this area. It will serve as an input into various formal sector strategies in which S\&T issues bear on the achievement of the Millennium Development Goals and the pursult of the World Bank's Corporate Advocacy Priorities, as well as on the creation of a climate for investment, jobs, sustainable growth and the empowerment of poor people. The paper argues that development will increasingly depend on a country's ablity to understand, interpret, select, adapt, use, transmit, diffuse, produce and commercialize scientific and technological knowledge in ways appropriate to its ambitions and level of development.

The paper analyzes the importance of S\&T for development, presents policy options for enhancing the effectiveness of S\&T systems in developing countries, reviews the previous expenence of the World Bank and other donors in supporting S\&T, and suggests ways that the World Bank can Increase its effectiveness through better integration of the work currently undertaken in S\&T. Its main messages are that: (1) S\&T has always been important for development, but the unprecedented pace of advancement of scientific knowledge is rapidly creating new opportunities for and threats to development; (ii) most developing countries are largely unprepared to deal with the changes that S\&T advancement will bring; (11i) the World Bank's numerous actions in various domains of S\&T could be more effective in producing the needed capacity improvements in client countries; and (iv) the World Bank could have a greater impact if it paid increased attention to S\&T both within strategies in particular sectors and by achieving synergies among on-going S\&T-related lending and grant activities in, inter alia, the Education, Health, Rural, Private Sector Development, and Environment sectors.

The role of S\&T in sustainable development is receiving vigorous attention in the context of the World Summit on Sustainable Development. The major international S\&T organizations are updatıng their strategies to reflect the renewed emphasis on S\&T that sustainable development requires. The United Nations, in particular, has identified five areas (Water, Energy, Health, Agriculture, and Biodiversity) as particularly critical for progress. The World Bank should be ready to play an appropriate role along with partner agencies in responding to the heightened demand for S\&T-related services in this new environment of S\&T prioritization.

The Importance of S\&T for Development. Science and technology have been central in the progress made to date in the fight against poverty and in stimulating economic growth. Today, however, the accelerating rate of progress in science and technology creates both tremendous opportunities and significant risks for developing countries. A lack of capacity among some developing countries to even access and utilize advances in S\&T has prevented them from capturing the benefits of S\&T that have become commonplace in the rest of the world. To date, the cost to developing countries of low S\&T capacity has been confined mostly to lost opportunities, such as in the failure to capture the benefits of the Green Revolution in Sub-Saharan Africa. In the future, active threats to, inter alia, food safety, natural capital, and human health will join lost opportunities in comprising the full costs of inadequate S\&T capacity. More specifically:

- In agriculture, advances in S\&T have facilitated higher yields, greater efficiency, and greater nutritional content in the world's food supply. Food production, however, must double in the 
coming decades to meet rising demand, and meet the challenges entailed $\mathrm{m}$, inter alia, improving resistance to drought, pests, salinity and temperature extremes; raising the nutritional content; and reducing post-harvest loss all in an environmentally and socially sustainable manner. At the same time, the regulatory challenges of assuring safety in food production and consumption will increase exponentially.

- In health, advances in scientific knowledge and its application have helped slow the trend of "high fertility, high mortality" and led to increasingly better health for many people in developing countries. Nonetheless, vector and water borne disease, AIDS, inadequate prenatal and maternal/child healthcare and other deficiencies continue to create a tremendous burden in the developing countries. Countries will be unable to correctly identify public health needs and choose cost-effective packages of health services if they lack S\&T capacity.

- Other problems, such as the needs of the 1.3 billion people who live without access to adequate fresh water, or whose health and livelihoods are endangered by emvirommemtal degradation call for development of new technologies (along with appropriate policy frameworks) to mitigate these problems and their effects on poor people. Timely local adoption often requires significant indigenous technological capacity.

- Access to affordable emergy is essentral for the two billion people currently living without electricity and is a pre-requisite for economic growth. Further advancement and application of research is needed to find new, environmentally and socially sustainable technologies that can meet the energy needs of developing countries.

- With respect to ecomomic growth, emerging evidence shows that-when an enabling environment for investment is present-the developing countries that are home to half the world's poor (Brazıl, China, India, Thailand, Mexico, Malaysia and the Philippines) are using technological capabilities to capture growing percentages of expanding global high tech export markets, and thereby adding to their rates of GDP growth. Other developing countries will need improved S\&T capacity if they are also to capitalize on opportunities for economic growth.

Science and technology in education pervade all of the above themes, with existing human capacity, training, research and application composing a significant part of the paradigm for the successful use of knowledge in any domain.

Policy Options for Reaping the Benefits from S\&T. Some middle-income countries have managed to create pockets of S\&T capacity that at least partially serve their economic and social ambitions. The vast majonty of developing countries, however, have severe deficits of S\&T capacity. Improvement depends on the adoption of appropriate policies and activities in at least four areas: human resources development, demand for knowledge in the private sector, public support of S\&T, and access to information and communication technologies (ICT).

- Policies for S\&T in human resources development aim to provide science education at the basic, secondary and tertiary levels, prepare young people to enter a diverse labor force that requires various levels of S\&T sophistication, and encourage the conduct of research and advanced training.

- "Implicit" policies for S\&T create an enabling environment that stimulates demamd for knowledge in the private sector through, inter alia, a stable macroeconomic environment, appropriate climates for trade and investment, credit policies, and an adequate intellectual property rights regime. "Explicit" policies for S\&T in the private sector aim to further break down barriers to the use of knowledge. These policies may include support for firm-based training to encourage technology deepening, increase industry-academia linkages and public- 
private partnershıps, establish protection for indigenous knowledge, provide tax incentives for firms engaged in R\&D, and stimulate "clusters" of knowledge-based industries.

- Policies for public support of S\&T must address the various aspects of the public role in the national innovation system, including: settıng priorities for funding and research, providing financing, instituting open, transparent peer-review selection processes, establishing governance, regulatory and management mechanisms, incorporating the results of research into public policy decisions, and monitoring and evaluating the system.

- Policies for information and communication technologies should seek to maximize the access to and flow of knowledge by, inter alia, extending access of avallable ICT to a wider range of users, improving the regulatory framework to facilitate a conducive environment for ICT growth, and providing training and education to faclitate broader use of ICT.

Lessons From Previous Experience in S\&T Capacity Building of the World Bank and Other Donors. Annual World Bank lending for S\&T is roughly $\$ 500$ million per year, about half of which is in the Rural/Agriculture sector. Most non-agriculture lending is to a small number of middle-income countries in East Asıa and Latın America. Another $\$ 100$ million in grants is provided to S\&T-related activities through the Development Grants Fac1lity. Total donor and foundation contributions are harder to quantify, but are estimated at roughly the same order of magnitude. The main findings from previous experience are that: (i) with the exception of Agriculture/Rural Development, no sector has given systematic attention to or pursued a coherent strategy to promote the appropriate role of S\&T for development, despite its recognized importance; and (ii) promoting S\&T requires a sustaned, coordinated multi-sectoral approach that has not yet emerged from the myriad of different activities that the World Bank has sponsored. Recently, more sectors appear to be recognizing the need for greater integration, but the progress made toward this goal has been modest and has come slowly and the timeline for anticipated results fals to reflect the longer time frame required for this type of change.

In particular, lessons such as those highlighted below have shown that effective policies for improving S\&T capacity in developing countries vary by country size, population, level of development, previous traditions, existıng capacity, and factor endowments. Smaller and poorer countries face a special set of challenges.

- Human resources development: Historically, the World Bank has not always emphasized science at the basic and secondary levels or the assessment of student learning outcomes. The support given has focused to a great extent on the provision of physical inputs at the expense of teacher training and curriculum development. The World Bank has been more successful with S\&T at the tertiary level in middle-income countries when investments have been made over a period of a decade or more.

- Stimulating demand for knowledge in the productive sector: Success in building technology capacity has been greatest when it has been linked to an explicit national science and technology strategy. In contrast, the disconnect of the productive sector from research and development was identified by OED as a factor limiting the success of technology development efforts. This is as true for goods and services with "public purposes" (e.g., health care, agricultural industries, etc.) as for other industries.

- Public support of S\&T: Effective projects were often those that helped institute open, transparent governance and peer review systems, linked research more closely to graduate training and higher education policy more generally, and ensured greater relevance of research. At the same tıme, a host of particular investments made through the DGF (including, but not limited to support for the CGIAR) show that targeted investments in research can yield high impact economic and social results. More recently, the World Bank 
has piloted support to improve research excellence through the adoption of international best practice funding mechanısms (e.g., competitive, peer reviewed selection, intensive human resources training, and investigator autonomy coupled with adequate research budgets) through the Millennium Science Initiative (MSI). The MSI can be successful if implemented flexibly and carefully, integrating it with the needs of a country's education system and its development prorities.

- World Bank experience in ICT: As the World Bank's ICT strategy paper establishes, investments in ICT infrastructure alone are not sufficient to create ICT capacity in developing countries: concomitant investments in human capital training and strengthening of regulatory frameworks are also necessary.

Analysıs of bilateral, foundation, and NGO S\&T capacity building initiatives reveals that significant positive results are achievable with small, targeted budgets aimed at specific S\&T-related challenges, particularly when the projects address all aspects of the challenge from the need for training to the necessity for linkages to the public and private sectors.

Rethinking the World Bank's Approach to S\&T and Developmene The World Bank's potential impact in promotıng S\&T capacity depends primarily on client interest and commitment. In addition, the degree of ownership of the issue within and across the World Bank's own Networks and Regions determines how timely and effectively we can anticipate and respond to client needs. Again with the exception of Agriculture/Rural Development, the World Bank's work on S\&T has most often been the result of interest from individual staff, teams or sectors. Going forward, active synergies will be achieved by the relocation of Science and Technology to the Human Development Network as of July 2002 to more effectively promote linkages with the Higher Education group. Additionally, a possible first step toward increased focus and ownership within the World Bank is to establish an internal S\&T Thematic Group with representation from both the Regions and from the Education, Rural, Health, Private Sector Development, Energy, and Environment Departments, plus the CGLAR and the DGF. The S\&T Thematic Group would consist of "champions" for S\&T from these sectors, who would coordinate, share knowledge, and identify opportunities for action. These opportunities would be linked to client demand, interest and commitment; would take into consideration the World Bank's comparative advantage in the specific area and country; and would be realized within the context of the World Bank's Country Assistance Strategies (CAS).

An improved World Bank approach to S\&T could, in principle, aim toward achieving the following goals:

- To increase awaremess of S\&T and its role in development: The World Bank could foster communities of practice within the organization itself so that sectoral and cross-sectoral S\&T issues can be addressed productively among the staff working on these issues and with the client countries. At the same time, the World Bank's comparattve advantage in dealıng with global public goods priorities and cross-sectoral S\&T issues would be leveraged internally as well as externally under the auspices of the WBI's outreach capabilities.

- To increase attemtiom to $\$ \& T$ im four key policy domaims (human resource development, promoting private sector demand, public sector support to S\&T, and ICT): Among the many actions that can be recommended in these areas, the World Bank might increase the emphasis on science education in basic and secondary education lending, include S\&T as part of the renewed and expanded emphasis on tertiary education, place emphasis on the creation of linkages between firms and knowledge institutions, reform enabling environments for better 
use of knowledge, help governments with their multiple roles pertaining to S\&T, and promote access to and use of ICTs.

- To achieve greater integration of on-going S\&T support: The World Bank could build on current "knowledge assessments" and pilot coordinated lending efforts across S\&T-related sectors (Education, Private Sector Development, Rural Development, Health, etc.) and promote other synergies among the S\&T-related initiatıves.

- To increase and strengthen S\&T-related analytical work: The World Bank could provide analysis and policy recommendations on global public goods priorities such as brain drain, food security and new agricultural technology, and effective S\&T education in developing country settings. The World Bank would also expand its participation in international scientific assessments (such as the IPCC and the Millennium Ecosystem Assessment) that have global public goods characteristics and produce policy-relevant knowledge on critical development issues.

- To foster collaboration with a range of international partners: The World Bank would support and buld upon the successful S\&T capacity bulding initiatives of various bilaterals NGOs and foundations, and increase professional contacts with representatives of the international science and technology policy community, including the OECD, UNESCO, the Third World Academy of Sciences, the Inter-Academy Council, the International Council for Scientific Unions, as well as national academies, science foundations, and especially experienced private sector partners and technology development specialists.

The ulimate aim of these actions would be to help the World Bank respond to the growing requests from clients, and to facilitate the appropriate attention to S\&T issues within Country Assistance Strategies that will lead to improved ability to use scientific and technological knowledge for the growing list of development challenges that require it. 



\section{STRATEgIC APPROACHES TO S\&T IN DEVELOPMENT}

Science and Technology (S\&T) are critical inputs for economic development and poverty alleviation. Advances in scientific and technological knowledge made possible the significant reductions of poverty and improvements in the quality of life in both developed and developing countries throughout the $20^{\text {th }}$ century. In the future, the ability of countries to access, comprehend, select, adapt, and use scientific and technological knowledge will increasingly be the determinant of material well-being and quality of life. As a development institution, the World Bank $^{2}$ can play an important role in helping its clients use science and technology for development.

Concern for the scientific and technological capacity of its clients has been a part of the World Bank's work since its founding, but attempts to raise S\&T capacity among clients has not always been sustained and systematic. Many World Bank initiatives, both in lending operations and through the Development Grants Facility, have focused on an array of S\&T-related issues (e.g., agricultural productivity, disease control, technical education, etc.), but these have never been articulated within a comprehensive vision or a plan for improving S\&T capacity across the board. With the acknowledgement of the importance of knowledge for development under the K4D Framework, there is room for rethinking this approach. Four of the World Bank's five Global Public Goods Priorities are strongly linked to S\&T (Communicable Diseases, Environmental Commons, Information and Knowledge, and Trade and Integration). Likewise, most of the Millennium Development Goals have a strong S\&T-component, and improved in-country S\&T capacity is directly required to reach, sustain, and monitor 24 of the $48 \mathrm{MDG}$ Indicators [See Appendix 1]. In addition, all the priority areas identified by UN Secretary General Kofi Annan (Water, Energy, Health, Agriculture, and Biodiversity) for the World Summit on Sustainable Development require advances in S\&T. The World Bank needs to respond to the growing demand for the S\&T services entailed in these challenges.

Reaping benefits from science and technology depends on a number of factors including: (i) investment in human resources training and development; (ii) the demand for knowledge by the private sector; (iii) public policies that provide the appropriate enabling environment for strong knowledge institutions; and, (iv) the level and quality of the information and communication technologies systems that permit the flow and dissemination of knowledge and information. When the policies and institutions oriented around these four factors are present in a given country and performance is high both within and between them, significant progress can be made in responding to problems associated with poverty and stimulating economic growth. When the appropriate S\&T infrastructure, which is composed of these four facets, is not developed, countries fall further behind, rendered stagnant by problems that other more technologically-advanced countries have long since overcome.

\footnotetext{
${ }^{2}$ The paper deals prumarily with the World Bank. Important future work will incorporate full consideration of the roles of all members of the World Bank Group.
} 
This paper seeks to underscore the importance of science and technology for development, the policies that can maximize the benefits of S\&T at the country level, and the strategic approaches that the World Bank and its partners can adopt to help accelerate the growth of scientific and technological capacity in the developing world. It proposes specific ways for the World Bank to integrate the isolated activities it currently undertakes in support of improved S\&T capacity, making future actions more targeted and effective.

The paper has three sections following this introduction. Section A addresses the state of the developing world's science and technology capacity. Section B discusses the policy options for reaping the benefits of S\&T. Section C presents lessons learned from World Bank experience and Section D discusses the implications of the lessons learned and explores avenues for renewing the role of the World Bank in S\&T capacity building.

It is cheaper and easier now than ever before to gain access to scientific and technological knowledge, thanks mostly to new information and communication technologies. But access to knowledge without the capacity to use it is worthless. Countries lacking adequate infrastructure to capture and use the increasing amount of accessible knowledge and information stand no chance to benefit from it. The needed infrastructure is a mix of human capacity, hardware, institutions, incentives, policies and investments. Finding ways to create and strengthen the infrastructure where it is absent is not simple, but the costs of inaction make it an imperative task.

The differences in capacity between the scientifically-advanced countries of the OECD and the poorer countries of the developing world are stark. OECD countries spend more annually on R\&D than the value of total economic output of 61 of the world's lowest-income countries ${ }^{3}$ (US $\$ 500$ billion versus US\$ 464 billion in 1998). ${ }^{4}$ Again, compared with low-income countries, OECD countries have twelve times the per capita number of scientists and engineers working in R\&D and publish 25 times more scientific journal articles per capita. In the OECD, the ratio of patents filed by nonresidents to those filed by residents is 3.3 to one, while in low income countries it is 690 to one. ${ }^{5}$ Of course, quantitative measures such as the size of R\&D budgets give only a partial glimpse of the situation; they fall short of describing the full range of differences in S\&T capacity. S\&T capacity is a multi-faceted ensemble of human, physical, organizational, institutional, and financial capital which defies reduction to a single set of indicators.

\footnotetext{
${ }^{3}$ The low-income countries, excluding China and India: Data from World Bank's World Development Indicators 2000.

${ }^{4}$ OECD Science, Technology, and Industry Outlook 2000.

5 Inventors must patent their inventions separately in each country in which they wish to have them protected. A single invention may therefore be patented in several dozen countries. Because of this, a high ratio of foreign to local patent applications indicates a low level of innovative activity among national researchers. Despite the other various factors that bear on the decision whether and where to seek patents, the ratio of foreign to domestic applications is considered a reasonably reliable indicator of national innovation effort.
} 
Developing countries are not alike in S\&T capacity. Brazil, China, and India may have more in common in S\&T-relevant sectors with OECD countries than with lowincome countries. No single set of policy prescriptions for improving S\&T infrastructure within developing countries could cover such a wide range of circumstances. For the purposes of this paper developing countries will be subdivided into three categories of S\&T capacity:

- Scientifically proficient countries increasingly define their relations with the scientifically ${ }^{6}$ advanced countries on the basis of equality or near equality; examples include Brazil, China, India, Hungary, and South Africa.

- Scientifically developing countries have pockets of adequate scientific and technological capacity amidst general scarcity; examples include countries such as Turkey, Colombia, Indonesia, Pakistan, and Latvia.

- Scientifically lagging countries lack capacity almost entirely; examples include countries such as Nepal, Albania, Mali, Ecuador, and Libya.

Depending upon where a country is situated within these three categories, the goals of S\&T policy will vary across a continuum of policy characteristics as briefly highlighted in Table 1. To the extent practical, the paper's recommendations will be tailored to the different needs of these three groups, ${ }^{7}$ with differences between country groups and their implications for policy being discussed in greater detail in the Policy Matrix in Appendix 2. However, it should be noted that there are likely to be significant differences between countries within the same overall category with respect to the four policy areas (human resources, demand from the private sector for S\&T, public management of S\&T, and the availability of ICT infrastructure). These differences will need to be reflected in the individual Country Assistance Strategies with regard to strengthening S\&T capacity.

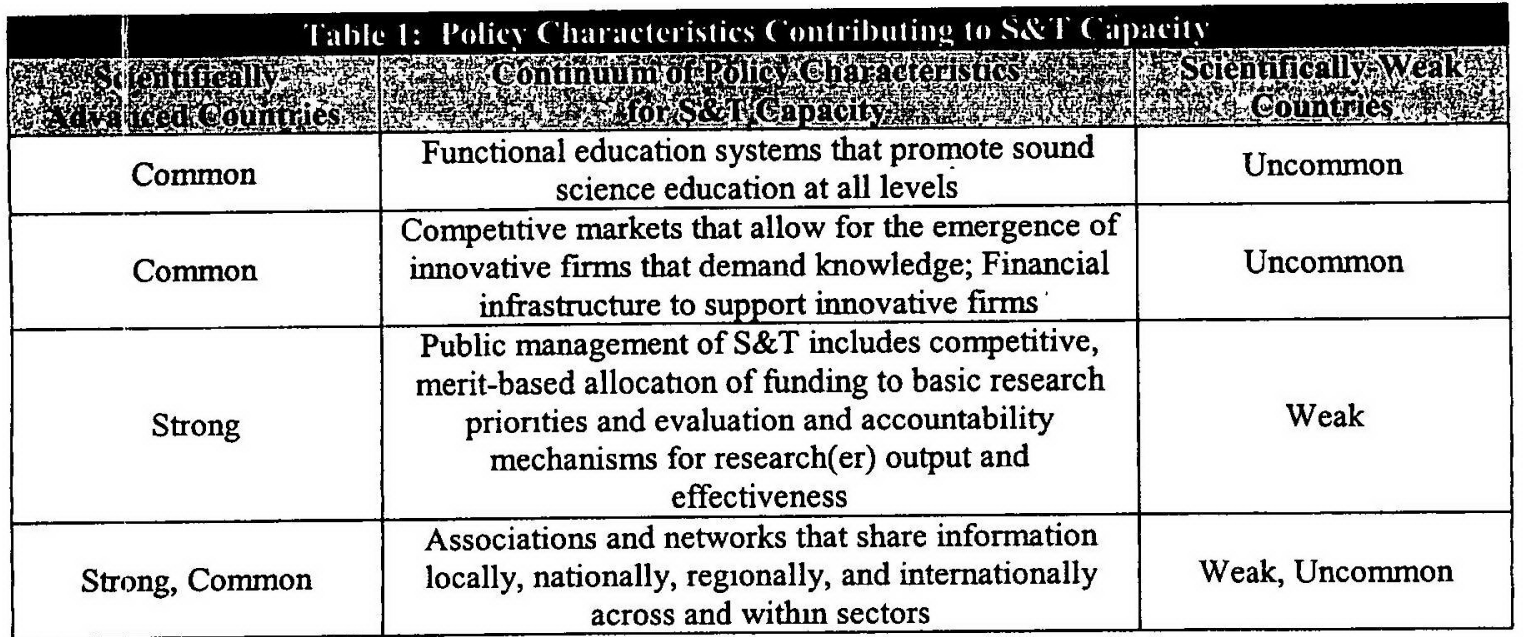

\footnotetext{
${ }^{6}$ For the sake of brevity, countries will be categorized as "scientifically" advanced, proficient, developing, or lagging rather than "scientfically and technologically" advanced, proficient, developing, or lagging. The latter term is more accurate, and use of the shorter term does not imply any bias against technological capacity.

${ }^{7}$ Differences span a continuum of the policy characteristics presented in this chapter and explored in more depth in Volume Two, Table 10, p. 27 and Appendix 2 of this volume.
} 
People tend to associate science and technology with the creation of new knowledge, through "frontier" or "cutting edge" research. Although this image has a strong hold on the popular imagination, it feeds a partial and biased view of what is important in functioning S\&T systems. While the returns to investment in appropriate R\&D for countries at a certain stage of development are well documented, the benefits of S\&T for the majority of countries come through the diffusion of knowledge, and its translation into goods and services via technological applications and engineering. These applications could be in classical industrial sectors like manufacturing, or in other sectors such as health, agriculture, and natural resource management. The vast majority of an S\&T workforce uses what a very few have discovered, adapting, converting and applying knowledge locally. Indeed, the main value of $S \& T$ in education is to create the human capacity to comprehend and apply, not to advance, knowledge in a given discipline.

Aiming policy to build this broader capacity for application of knowledge is especially important for developing countries. Initially, the bulk of benefits are likely to accrue from thousands of small scale technological improvements in small and medium enterprises (SMEs), not through investments in large-scale corporate labs. Improved technology development at the SME level, however, helps create income that can finance, among other things, future investments in S\&T.

For highly resource-constrained countries, focusing on knowledge advancement or cutting edge research is costly and unwise (Box 7 in Volume Two provides more detail regarding the specific challenges faced by smaller, poorer countries in building science and technology capacity). Clearly, no country or culture, rich or poor, has more inherent potential or talent for advancing knowledge than any other. But rich countries have, through decades of continuous investment in human capacity and institutions, built infrastructures that better allow the potential of science and technology as a social endeavor to flourish. Once in place, the infrastructure helps create the wealth that funds future investment. At the same time, the infrastructure acts as a global magnet, drawing into itself talented individuals from abroad. Countries wishing to reap the benefits of S\&T should seek to put in place this broad infrastructure that captures existing knowledge, and employs it in wealth-enhancing investments in improved health, environment, and technology development for economic opportunity. While the timeframe for such change is long, this is the surest path toward fuller eventual participation in knowledge generation and cutting edge research.

The list of issues for which developing countries need scientific and technological expertise grows longer daily: agricultural productivity, health, sustainable use of natural resources, education, creation of economic opportunity, etc.. At the same time, scientific advances are defining new challenges (e.g., the environmental and human health issues associated with genetically-modified organisms) that many countries find themselves poorly prepared to handle, given the increasingly sizeable divide separating the scientifically advanced OECD countries from the rest.

Science and technology capacity is not the only factor relevant to development. It is one component within a set of factors-along with policies favorable to competition, 
sound fiscal and macroeconomic policies, accessible quality education, affordable and accessible health services, and good governance - that build the climate for investment, growth, and empowerment. These factors are mutually dependent, and strength in complementary institutions becomes more important to science and technology the more deeply they permeate a society and economy. At the same time, the stronger complementary institutions and policies become, the more S\&T can contribute to overall development.

\section{The Importance of S\&T to Development}

Science and technology are intimately connected with development because: (i) they have a historical record of bringing advances that have led to healthier, longer, wealthicr and more productive lives and (ii) they are key ingredients to solutions to the most serious poverty alleviation and economic development challenges that we currently face and are likely to face in the future. The many ways in which science and technology impact poverty alleviation across various sectors and economic growth merit attention.

\section{For Poverty Alleviation}

Advances in science and technology are, in many ways, the ultimate Global Public Good: once discovered, their benefits can be extended to additional users at little or no marginal costs. In the most basic and critical areas of human need, science and technology have made possible significant progress to date, and they hold the best prospects for continued progress, particularly with respect to agriculture, health, energy, water, and environmental concerns.

Agriculture: In the domain of food security, advances in S\&T provided the foundation for the Green Revolution, and have allowed food prices to remain at historical lows for the past several decades. Improved knowledge of plant biology and breeding techniques led to better seeds and cultivation practices that drastically increased yields [See Figure 1]. Not surprisingly, Africa, the region of the world with the lowest indicators for S\&T capacity, has had the greatest difficulty in capitalizing on and benefiting from the Green Revolution. Throughout the rest of the developing world, yields rose much faster than the population increased, mitigating pressures to extend cultivation to scarce additional land. It is estimated that, without the scientific advances of the past 50 years, an additional land area the size of Europe would be required to produce the world's current agricultural output. Nonetheless, over 800 million people remain food insecure, and global food production will have to double in the next 30 to 50 years to keep pace with growing demand. Rapid advances in the understanding of plant biology and related areas (especially via genomics) hold hope for solutions to problems as varied as increased productivity, nutritional content of food, food as a carrier of vaccines, soil/land degradation, post-harvest loss, and drought and pest resistance. Unfortunately, the majority of cutting edge research in these fields is performed in private laboratories and focuses on profit opportunities in OECD countries rather than on issues that are of greatest concern to the well being of poor people. 
FIGURE 1: WhEAT YIELDS IN ARGENTINA AND INDIA CORRIELATING TO

THE SCIENTIFIC RIEVOLUTION (Average Annual Yields in 1,000 Kilograms/Hectare)

- Argentina India

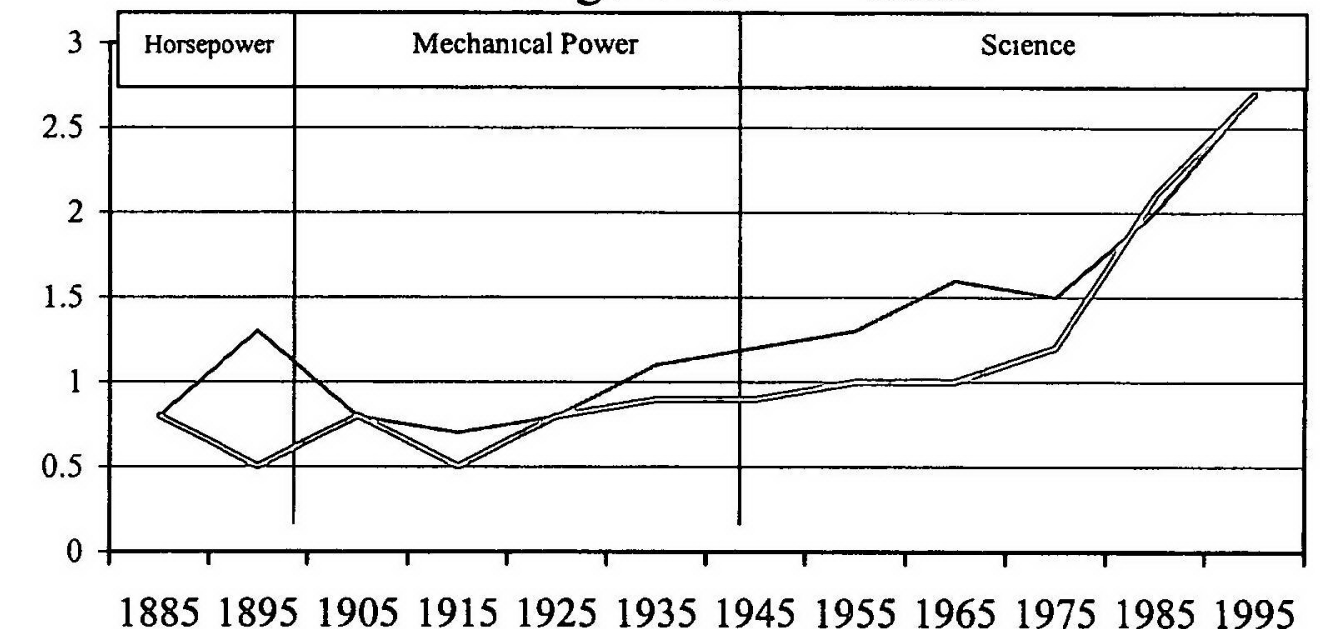

188518951905191519251935194519551965197519851995

Adapted from Pardey, Chang-Kang and Alton 2001

Health: Ill-health is both a cause and a consequence of poverty. Over the past century, science and technology provided the basis for the largest ever aggregate improvements in human health. Life expectancy is up sharply worldwide [See Figure 2 on the following page]. Certain scourge diseases have been eliminated, (e.g., smallpox) while the morbidity and mortality associated with everyday health-related events like childbirth and routine infectious disease have declined sharply. In health, the cumulative effects of scientific advances are very evident: while health indicators have always varied with income, during the $20^{\text {th }}$ Century, the same real increase in income led to progressively greater health improvements. As knowledge accumulates, the same money buys increasingly better health. Still, progress is good but uneven. The developing world still accounts for a disproportionate amount of the global burden of disease, and research spending on health is severely skewed away from the concerns of developing countries. Far too many countries are trapped in cycles of "high-fertility, high mortality" that the world's better-off countries have broken. Indoor air pollution, dysentery, water-borne disease (e.g., cholera), vector-borne disease (e.g., malaria, dengue, etc.) and AIDS account for millions of deaths annually and are hitting hardest the countries that are least prepared and can least afford to deal with them. Some of these issues can be addressed using current knowledge, (e.g., dysentery) while still others require scientific breakthroughs in S\&T (e.g., AIDS and malaria).

Figure 2 illustrates changes in life expectancy at birth in the developing world, presented by region, as compared to the developed world. As the figure shows, from 1960 to 1998 many regions have begun to catch up to the high income countries' average life expectancy. However, the grim improvements in some regions, such as Sub-Saharan Africa, illustrate the need for continued attention to the inequities in health attainment. 
Figure 2: Life Expectancy at Birth in the Developing World

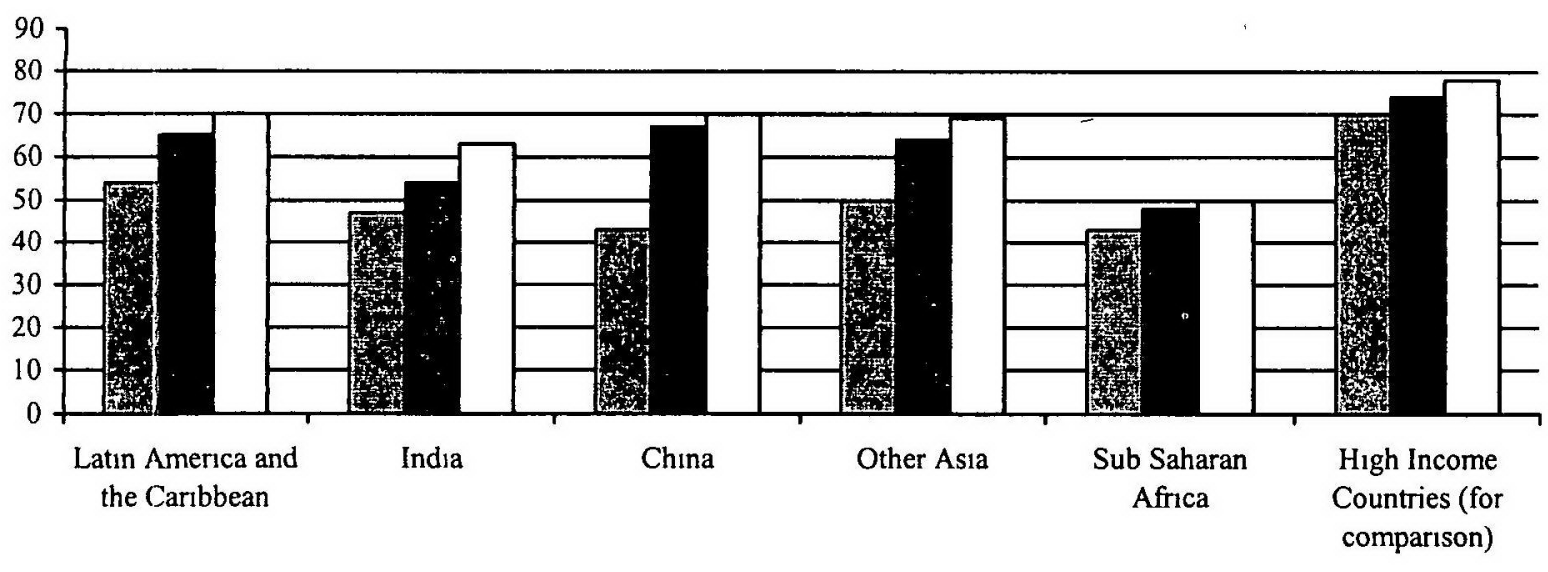

图 $1960 \square 1980 \square 1998$

Box 1 below draws on examples from the health sector to draw out the complexities in the relationship between knowledge, diffusion and outcomes. As the box describes, advances in S\&T make possible, but do not guarantee, progress against poverty.

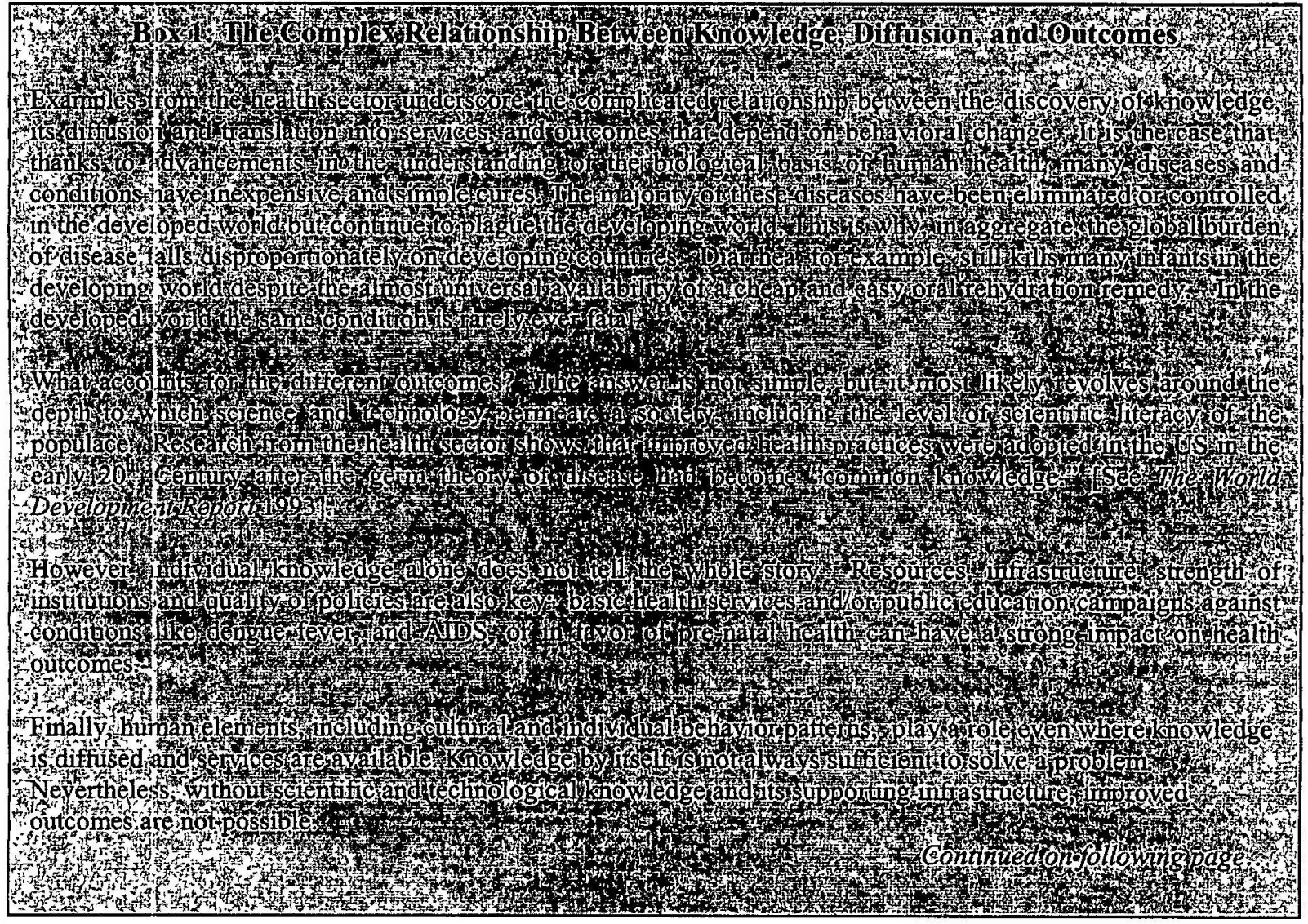




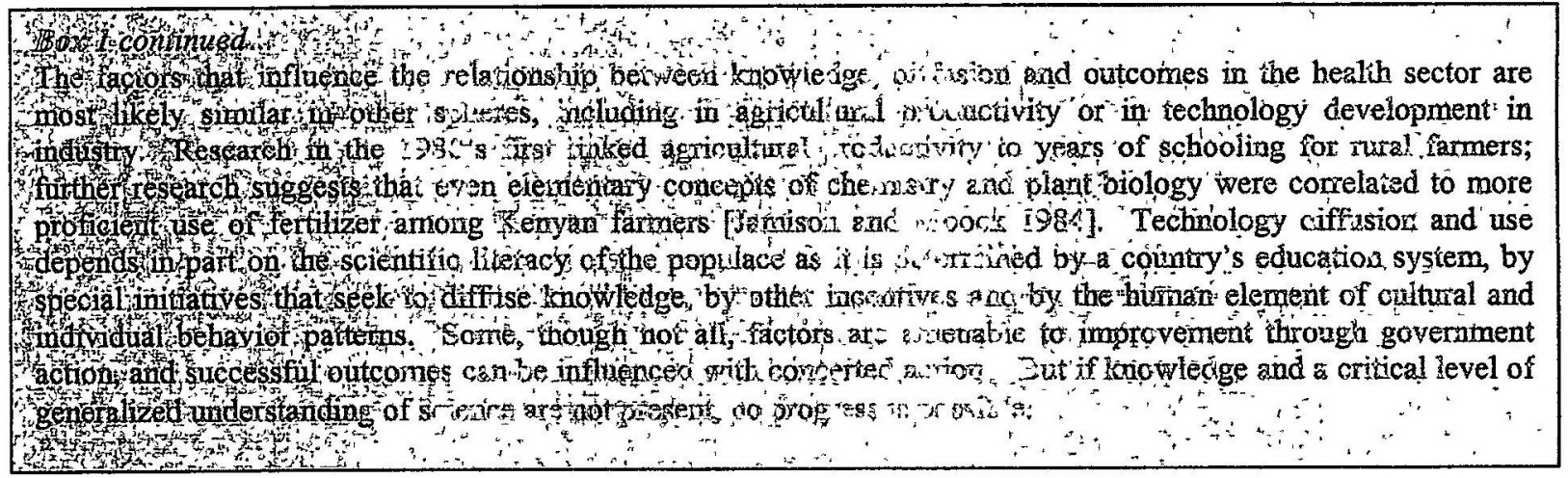

Energy: Despite its importance to economic growth and poverty alleviation, energy continues to be exploited in a short-sighted and unsustainable way. Unfortunately many countries are promoting fossil fuel energy policies and practices that are causing environmental degradation at the local (particulates and smog), regional (acid deposition) and global (climate change) scales, leading to significant loss of human life and ecological damage. Currently, two billion people in the world are without electricity. A central question to be answered in addressing the energy needs of this one third of earth's population is-how do we adequately address the growing energy needs of the world's population without exploiting the natural resource base and compromising the environment? Modern clean, renewable energy technologies (e.g., solar, wind, modern biomass) need to be developed further and there needs to be an increase in the efficiency and sustainability of energy use in transportation, industry, and housing. Depending upon projections of population and economic growth, technology change and the growth rate of different information markets and governance structures, global primary energy use by 2100 is predicted to range from a low of $514 \mathrm{EJ}$ to a high of $2,683 \mathrm{EJ}$, while $\mathrm{CO}_{2}$ emissions are predicted to increase to between $2.7 \mathrm{Gt}$ and $36.7 \mathrm{Gt}$ [IPCC 2000]. ${ }^{8}$

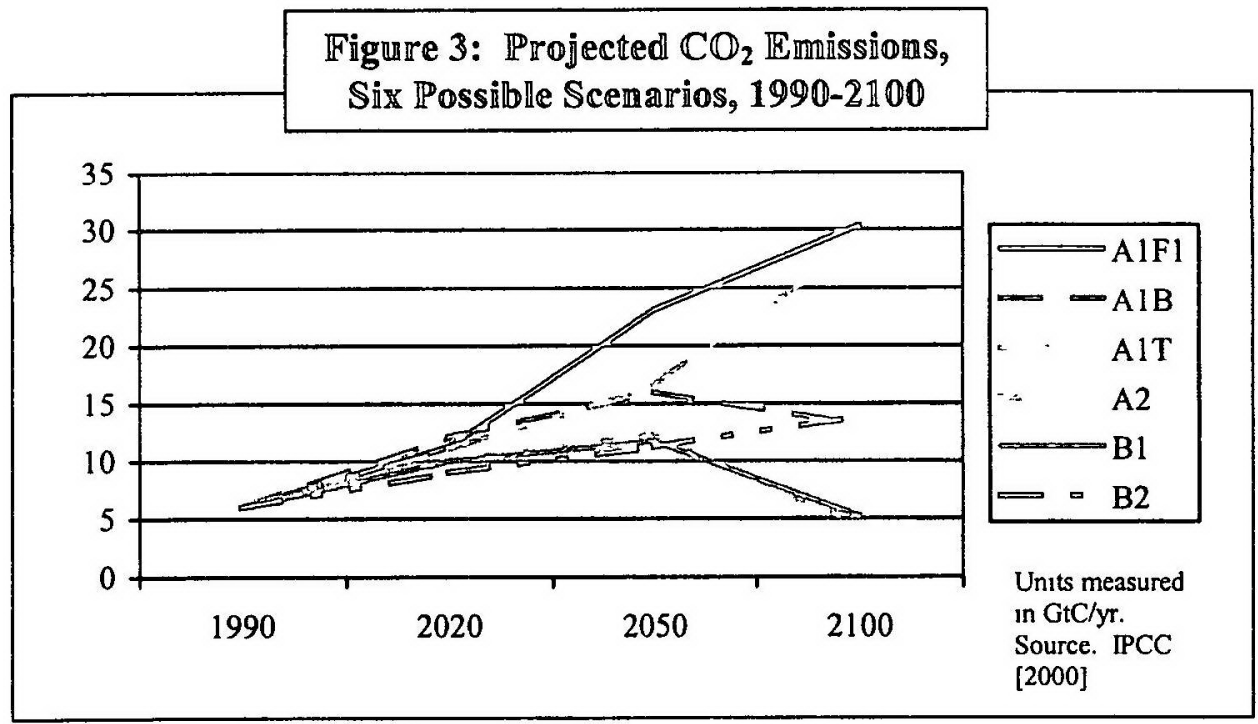

8 Emissions scenarios coded in Figure 3 correlate with the six illustrative scenarios used by the IPCC in their 2000 publication Emsssions Scenarios See publication for description of scenano characteristics. 
Water: Water is another vital but scarce resource for which, in the absence of technological innovation, current and projected use patterns can only lead to severe crises. Today, about 1.3 billion people lack access to an adequate supply of safe water, two billion people do not have access to adequate sanitation; and water pollution causes millions of preventable deaths each year, especially among children. Water pollution is expected to continue to degrade freshwater and marine ecosystems, with a significant loss of biodiversity. The challenge is to leverage new technologies to provide an adequate supply of "safe" water in urban and rural areas to all users in a growing-wealthier population: households, agriculture and industrial sectors (e.g., inexpensive desalination technologies).

Environment: Environmental degradation at the local, regional and global scale adversely affects the livelihoods, health and vulnerability of poor people. Local issues include indoor and outdoor air pollution and water pollution, regional issues include acid deposition, and global issues include climate change, stratospheric ozone depletion, loss of biological diversity, land degradation and desertification. These changes in the environment can adversely affect the incomes of poor people who depend on natural resources for their livelihood. These changes may also adversely affect human health through air and water pollution, an increase in the exposure to vector-borne diseases such as malaria and dengue, and an increase the vulnerability of poor people to extreme weather phenomena (e.g., floods and droughts) and sea level rise due to climate change. Hence, environmental degradation threatens poverty alleviation and long-term sustainable development.

The key challenge is to recognize that local, regional and global environmental issues are inextricably linked and affect sustainable development. Therefore, there are synergistic opportunities to develop more effective response options to these environmental issues that enhance benefits, reduce costs, and more sustainably meet human needs. The capacity of countries to adapt and mitigate can be enhanced when environmental policies are integrated with national development policies.

\section{For Economic Growth}

Science and technology are strategically important to economic opportunity and growth. For many years policymakers have suspected a close link between economic growth and productive investments in S\&T, and now mounting evidence supports this, in three principal ways.

First, since the industrial revolution, rich (developed) countries have had the most S\&T capacity and have grown fastest. From 1870 to the present, scientifically- and technologically-advanced countries have become increasingly wealthy, and their rates of growth have not diminished as this occurred [Pritchett, Divergence Big Time 1995].

Second, returns to R\&D have been shown to be consistently positive and high across virtually all industries examined, in the developed and (more recently) the 
developing world. These findings have helped establish a correlation between innovation and growth. In a host of categories, different measures of knowledge inputs to production continue to increase, and measures of the returns to these inputs outstrip those to less knowledge-intensive production. The evidence confirming the positive returns to investments in knowledge is vast. Recent meta-analyses summarized 57 published studies of rates of return to industrial $R \& D$ at both the firm and the industry level [OECD 2001] and 292 published studies of agricultural R\&D demonstrated consistent high double digit returns [Pardey 2001]. Moreover, as the recent flagship report on closing the gap in education and technology [LAC World Bank 2002] confirmed, within the context of the knowledge economy framework, the "interaction between technology and skill is critical in determining growth, productivity and the distribution of earnings."

Third, and perhaps most important from the perspective of the World Bank, technological capacity appears to be contributing to accelerated growth in some large developing countries (e.g., China, India, Brazil, Mexico, Philippines, Thailand, Malaysia). High tech manufacturing exports have grown faster than all other categories and developing countries are gaining a larger share of this expanding trade. These developing countries, which are now benefiting from a combination of technological capacity, openness to trade and other comparative advantages (such as lower wages), are also experiencing accelerated rates of economic growth. What is more, the countries benefiting are home to over half the world's population, and more than half of the world's poor. Additional evidence [Dollar and Kraay, 2001] shows that incomes of poor people are rising proportionally with growth rates.

Table $4 \mathrm{a}$ and Figures $4 \mathrm{~b}$ and $4 \mathrm{c}$ on the following page present the quantitative evidence for the correlation between increased technology content of exports and GDP growth. ${ }^{9}$

9 For an annotated listing of recommended reading relevant to S\&T and economic growth as well as S\&T and each of the sectors covered in the preceding sections, consult the annotated bibliography in Annex 6 of Volume Two. 


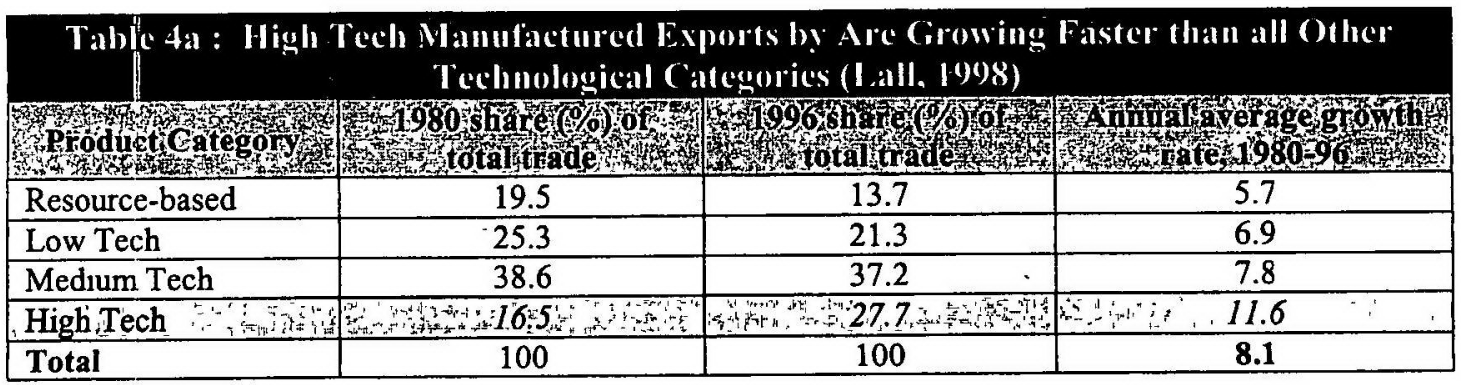
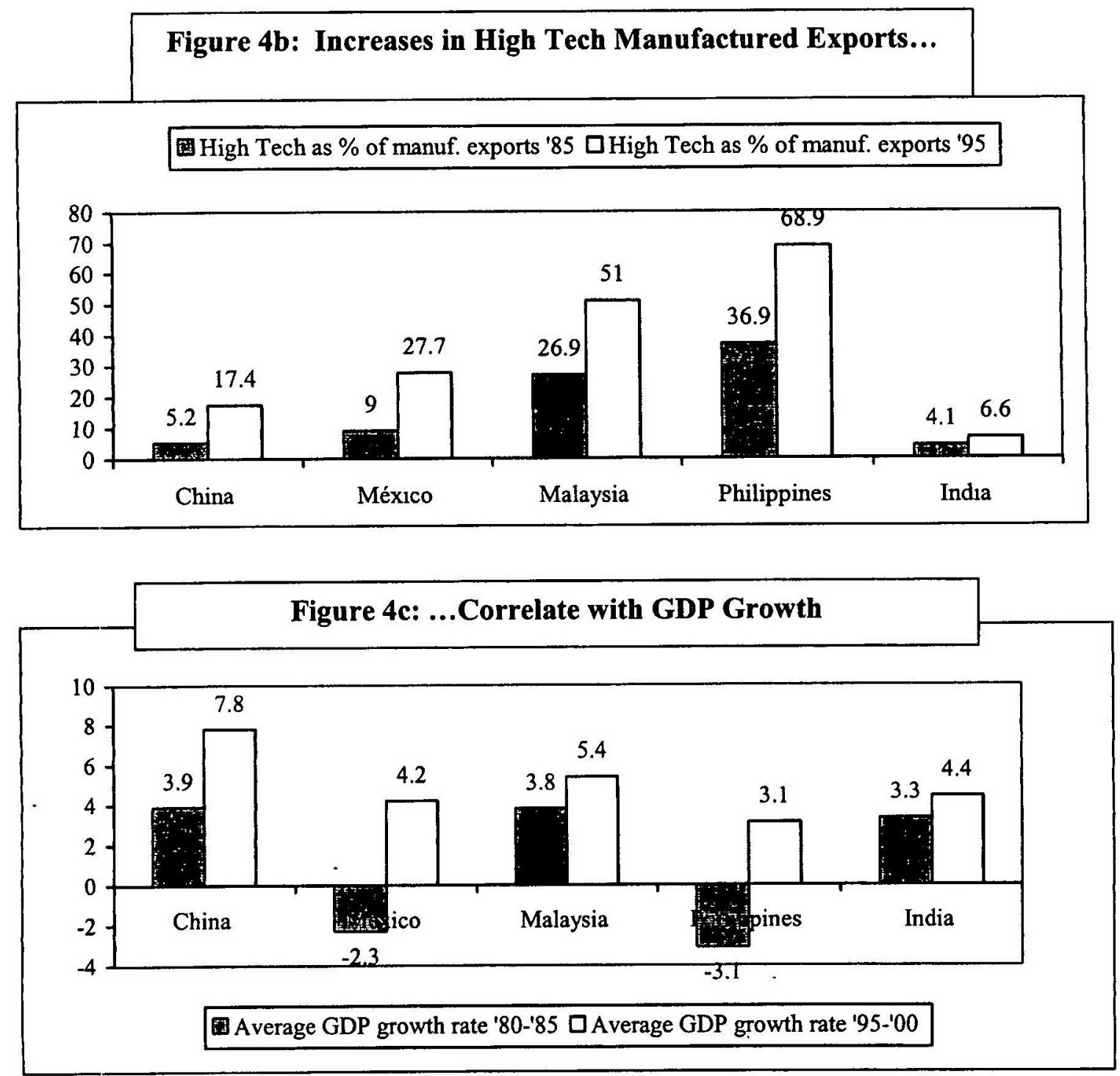


\section{Policy Options for Reaping the Benefits of S\&T}

The effects of S\&T on poverty and economic growth underlie their importance for development. However, achieving progress in S\&T capacity depends on good policies and practices that foster the appropriate environment implemented consistently over the long term. The framework for these policies must recognize the interconnectedness of the areas upon which S\&T bears. Policies that affect human resources development, demand for knowledge from the private sector, public support for and management of knowledge institutions, and access to information and communication technologies (ICT) infrastructure must be coordinated and harmonized in order to create the conditions in which S\&T capacity deepens and consolidates. Each of these areas, which are detailed in brief in the following pages, entail a set of specific sub-policies, yet success depends on integrating them harmoniously. Different countries, of course, face different challenges that require emphasis in one area or another. ${ }^{10}$

Policies for $\mathbb{H}$ mman $\mathbb{R}$ esources $\mathbb{D e v e l l o p m e m t}$ Policies concerned with human resource development seek to accomplish four major goals that are briefly highlighted below.

$>$ Provide the broad basic science education that makes a human resources base scientifically literate, imparting both everyday skills and intellectual abilities needed for an informed citizenship

$>$ Stimulate interest and prepare adequate numbers of young people to pursue careers in science and technology as well as provide opportunities for life-long learning and skill renewal

$>$ Educate a diverse labor force and develops skills for various purposes at various levels of sophistication

$>$ Encourage the conduct of research and advanced training that creates the knowledge and highly trained specialists needed to advance the frontiers of knowledge and applications

Sound human resources development for S\&T begins with science education at the primary and secondary levels. Student achievement outcomes in science in much of the developing world are very low. ${ }^{11}$ Of course, many of the problems of science education at primary and secondary levels cannot be separated from the more generalized challenges in basic education, such as teacher training and recruitment, stable education finance, availability of teaching materials, etc. Other challenges are specific to the domain of S\&T. These include curricula that are appropriate and science programs tailored to the developmental needs of students and their societies, the use of goals and standards for student achievement to guide the design, implementation, and assessment of all elements of the science program, and provision of support systems for teachers that align with the goals of the science program.

10 Appendix 2 summarizes how the policy area of emphasis for S\&T growth differs with the varying capacities of developing countries.

11 See the results from the TIMSS for a more detailed description at www.timss.bc.edu. 
As students progress through the education system, scientific and technological education opportunities should deepen and differentiate within a context of lifelong learning. Between the general scientific literacy that is part of secondary education, and the advanced programs pursued by university-bound students, a critical middle level of technical skill needs to be developed. Secondary-level science education should stimulate learners and encourage students to pursue careers in $S \& T$, whether as technicians, engineers, or researchers. To do this, and to provide opportunities for lifelong learning and skill-updating requires an array of technical and professional schools, community colleges, and other intermediate S\&T institutions. Technical and professional schools often seek to provide mid-level technical skill to large numbers of students in areas with strong immediate labor market demand.

More advanced training opportunities will be offered by a different set of institutions within a country's tertiary education system. These might include regional and national universities, as well as research universities and institutes. Often, research universities and institutes are the locus of a country's main efforts in knowledge production and advanced human capital training in S\&T. Without the necessary policies that encourage the proper functioning, growth and reform of the diverse institutions that work together to educate a country's populace, it is unlikely the resulting workforce will be trained in the relevant skills needed to drive a complex and growing economy. The reform and improvement of tertiary education systems is a domain unto itself, and the challenges here are many and important. Options for reform in tertiary education generally are discussed in the Bank's 2002 tertiary education paper, "Constructing Knowledge Societies: New Challenges for Tertiary Education." That paper and this one are complementary and are intended to be read and disseminated together.

Promoting research quality is a delicate institutional balancing act. Some issues are general and affect tertiary education and research institutions of all types. These pertain to the quality of faculty, the relevancy of curricula, the adequacy of physical resources, the flexibility and autonomy of institutional management, and the sources and stability of financing. A major challenge facing developing countries is how they can meet the growing demand for tertiary education while simultaneously improving quality and relevance, within shrinking public budgets. The growing role for the private sector in higher education is another phenomenon that requires attention. These issues acutely affect education in science and engineering, which tends to be more complex and expensive, particularly in research-intensive subdisciplines.

Other issues are specific to science and technology itself; they revolve around assuring the linkages between graduate education, the private sector and publicly-funded, university-based research systems. The latter relies on competitive allocation procedures; transparency, and peer review; research evaluation and accountability for results; special programs, national priorities, and perhaps most important, the adaptability of the system to changing conditions and new challenges. Another critical issue in tertiary education is how to balance public support for foreign and domestic training to strengthen domestic capabilities and avoid brain-drain by individuals educated at public expense. 
Policies for Stimmulatimg $\mathbb{D e m a m a l}$ for $\mathbb{K}$ mowledge im the Private Sector Highly skilled human resources for science and technology cannot in and of themselves produce benefits for a society. They must act within a structure in which the private sector requires and seeks knowledge. Countries that have transformed their economies and dramatically improved income levels have done so by improving the technological performance of their industries within supporting investment climates. They have deepened their technological capabilities and services to the point where they can consistently and successfully compete on a global scale in a growing number of industries. They have recognized that economic performance is more sustainable when it is founded on the dynamic advantage of flexible production and cost reduction, rather than on the static advantage of low-cost labor or factor endowments. They have combined policies for investment that encourage and reward entrepreneurship with those that facilitate the greatest flow and use of commercially-relevant knowledge. Transformations did not occur overnight; in general, they required two to three decades of sustained national effort. While each experience has been different, some basic lessons have emerged. In general, countries did not "leapfrog" from archaic to modern technologies. Instead, as one observer put it, "they engaged in a painstaking and cumulative process of technological learning (from imitation to innovation)."12 In many cases, they focused a broad-based strategy on technology development at the level of the SME, rather than on support to cutting edge R\&D.

Demand for knowledge in the private sector should not be limited to classical industrial sectors such as manufacturing. It is equally important to stimulate this demand in areas such as agricultural productivity, health services, energy services and natural resource management, in both firms and government institutions. This stimulation of demand may occur through both explicit and implicit policies, examples of each are provided below.

A number of "explicit" policies may be appropriate at the level of the firm. Such policies are generally intended to overcome information barriers to understanding or appreciating the potential benefits of $R \& D$, or to lower the cost of risk-taking. These goals may be accomplished through a variety of interventions that foment strong university/industry relations and labor market-linkages, including tax or other incentives to firms for cooperative pre-competitive research, commercialization of publicly-financed research, sponsorship of "scientist-in-industry" programs, provision of joint or specialized training, and other similar activities. Success in industry-science relations often relies on informal, person-to-person links that are best promoted through a diverse set of interactions, which create cultures of information exchange. Successful cultures of this kind seem to emerge when labor is mobile, incentives are aligned, basic research results are shared, and rigorous evaluation of research is conducted. The creation of shared infrastructure for new firms in the form of technology parks or "incubators" can be a means of promoting the desired interactions, but such ventures have a mixed empirical record of success. Best practice lessons are now emerging for technology parks and incubators that reflect the need for long time horizons for commercial

12 Bezanson, Keith, and Geoffrey Oldham, "A Science Technology and Industry Strategy for Vietnam," p.37. This section of the paper draws on this work as well as on conversations with the authors. 
sustainability, careful matching of target markets with the strengths and ambitions of potential firms, and proximity and linkages to top quality research institutes and universities. $^{13}$

"Implicit policies for S\&T", which create a supportive environment for investments in scientific and technological undertakings, are virtually identical to those that build the climate for investment, jobs, sustainable growth and empowerment of poor people more generally. These may include, but are not limited to:

- Basic Macroeconomic Stability. While desirable for a host of reasons, avoidance of fiscal and monetary crises helps provide the stability and continuity needed for the finance of research and commercialization.

- Openness to Trade and Foreign Direct Investment. While some countries have managed to improve scientific capacity and technological performance through strictly domestic measures, the weight of the evidence is showing more cases in which trade and FDI were critical conduits for the technology transfers that spurred growth. ${ }^{14}$

- Credit Policies. If a diverse set of financial instruments (loans, equity financing, venture capital, etc.) do not evolve as technological capacity increases, industrial development can be stifled.

- Intellectual Property Rights Protection. IPRs are effective when they balance individual interest to control, set the terms of, and profit from the use of an invention with collective interest to stimulate innovation by encouraging the publication and diffusion of new discoveries, to assign rights through due (judicial) process, and to override these rights partially or fully when a greater social good is judged to warrant this. When properly balanced, IPRs facilitate investments to develop and commercialize inventions and can stimulate technology transfer (refer to the more detailed discussion of IPRs in Volume Two, page 43).

- Competition Policy. Policies that create a level playing field and facilitate the entry and exit of firms into new markets stimulate innovation and commercialization of new technologies.

- Provision of Industrial Standards. This can either take the form of a pure public good, in which the government creates and maintains standards that permit technology based commerce, or, simply creating an atmosphere in which firms themselves agree on such standards to facilitate open interchange and use of specific technologies.

13 For a more detailed look at the way in which demand is stimulated in the private sector, Volume Two, Annex 5 provides a study of the role of the private sector in facilitating the acquisition of technology in developing countries.

14 Openness to trade may often accompany growth that is fueled by technology development, but it is not true that openness is an indispensable prerequisite for S\&T-led growth in all cases. Some countries have developed strong industrial bases with relatively closed economies. Openness, like the other items mentioned here, might be best considered a likely associated condition, to which there are exceptions. See Nelson, Richard National Innovation Systems: A Comparative Analysis (New York: Oxford University Press) for further detall. 
Policies for Public Support of S\&T The public sector has played a significant role in all countries that have developed strong S\&T capacity. This role should have clear boundaries, limited in many cases to identifying priorities, creating incentives and frameworks, funding basic research, and providing S\&T-related public goods. Lately, the role also involves stimulating linkages between public and private sector entities. Nonetheless, public action will always be a part of the creation and maintenance of an S\& $\Gamma$ system, as many of its features have public goods characteristics and would be undersupplied by the market alone.

The proper functioning of the public sector, be it with respect to the private sector, education and training, or technology transfer and information flows, is critical to the creation and maintenance of a well-functioning S\&T system. Conceptually, the public role can be disaggregated into five functions:

$>$ Setting priorities for public sector financing

$>$ Directly financing some parts of the system

$>$ Governing, regulating, and (partially) managing the system

$>$ Incorporating the results of research into public policy decisions

$>$ Monitoring and evaluating the system to ensure accountability and relevance

These responsibilities come together in a cycle of continuous revision and formulation of S\&T policies that determines the size, character, and effectiveness of a given system. Effective S\&T systems emerge when governments are constantly engaged in this cycle of priority setting, policy formulation and implementation, execution, use, monitoring, and evaluation.

One such area in which a number of functions come together, requiring a knowledgeable yet flexible government is that of setting the research agenda. The goal is to strike the proper balance between the need for basic and applied research while achieving breadth that connects research to important national priorities.

Box 2 considers the ways in which these issues are evolving in the policy sphere. 


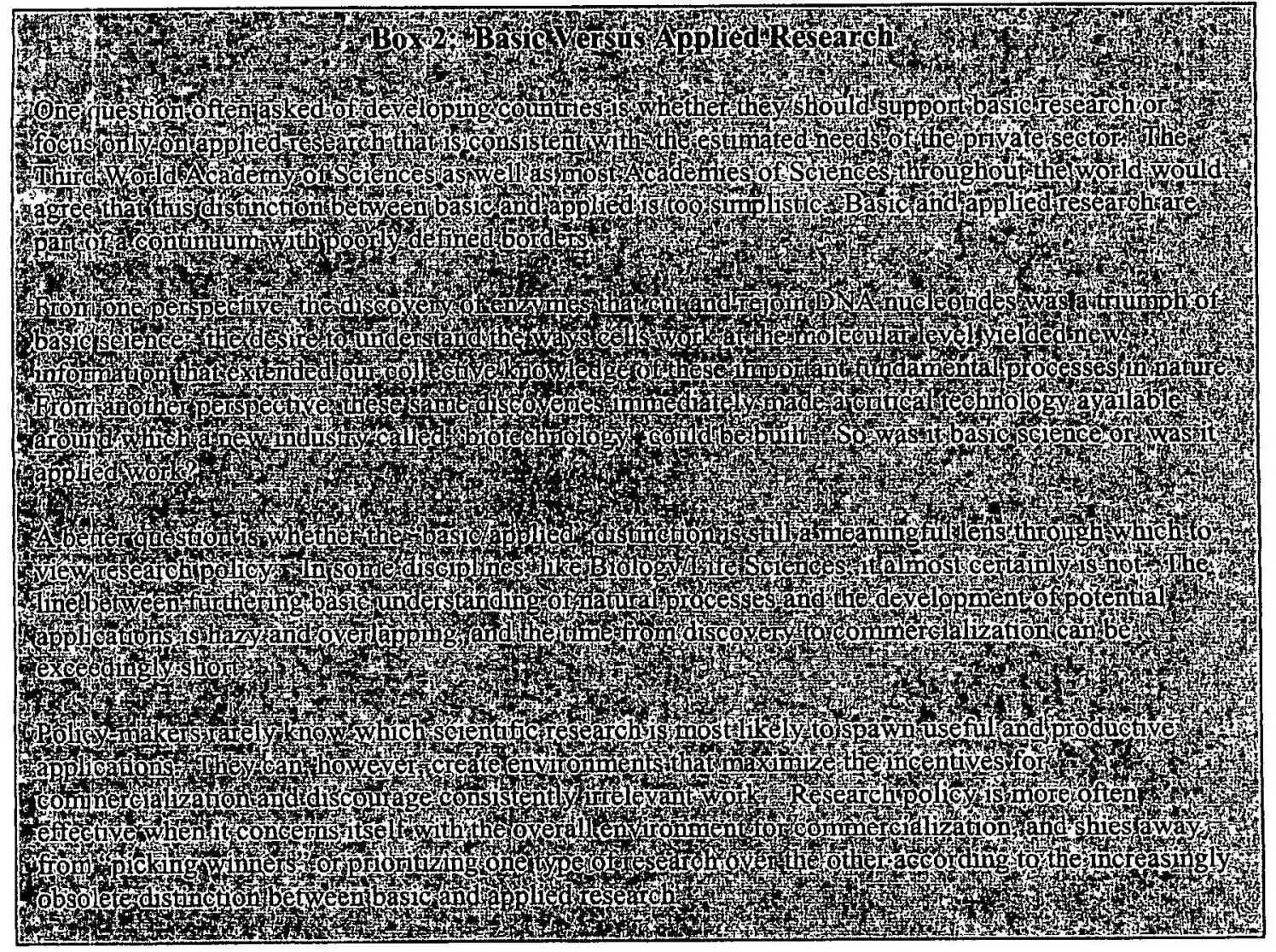

The challenge in this policy area is to provide effective public support for S\&T through a variety of channels simultaneously. First, governments must set national priorities and assure that the S\&T system is diversified and decentralized, again, balancing concentration of resources in centers of excellence with stimulating large-scale and dispersed research efforts. Second, they must play major roles in organizing and sustaining education systems and sectoral ministries that either produce or require S\&T inputs and outputs. This is done through balancing their roles as producers, consumers, financers, managers, and regulators/controllers of quality for research and its accompanying human resources training. Third, it is also necessary for governments to play a critical role in establishing the rules of the game of S\&T resource allocation. A major part of this involves promoting transparency, objectivity, and peer review and evaluation procedures, assuring that merit and performance are the criteria for determining how to award discretionary research funding. Fourth, governments must seek to inform their policy decisions with the necessary scientific data. Finally, as monitors and evaluators of a transparent and impartial S\&T system, the government has a role to ensure that women and other traditionally-excluded groups have access to the same opportunities as men to build and advance careers in science and technology. The gender dimension of S\&T in development is one requiring particular attention from public sector agents as women are egregiously under-represented in most science- and technology-related professions and global poverty and its consequences fall 
disproportionately on women, whose historical lack of empowerment has marginalized their voices in many of the decisions that affect their lives (see Volume Two, pages 54-56 for further discussion).

Policies to Promote Adequate ICT Imfirastroncture Information flows are an essential part of the overall structure that promotes the use of knowledge. Adequate information and communication technologies (ICT) infrastructure is now indispensable to ensure access to the global stock of knowledge and information on which innovation depends. ICT infrastructure has created new channels that rout information more efficiently, reducing transaction costs and making possible new and/or greater economic opportunities. In research specifically, new technologies for information storage, organization, and sharing are changing the nature of research in a number of fields. New disciplines like bioinformatics concern themselves exclusively with the discovery and organization of massive quantities of data on living organisms.

As in other areas for S\&T capacity building, the challenge for the vast majority of developing countries is to access available ICTs rather than to generate new ICT research. Policies that expedite the process of helping cities, regions and whole countries to become physically wired are critical to narrowing the divide between the scientifically advanced and the scientifically lagging. The nexus between private industry, educational systems and the pubic sector stands to gain as well from improvements in ICT capability as connectivity fosters communities of knowledge and practice capable of addressing innumerable cross-sectoral development-related objectives. Countries that lack adequate ICT infrastructure are excluded from the efficiency gains related to ICT modernization and the opportunity to benefit from further knowledge made available in ICT-dependent forms, as explored in more depth in the recently released ICT Strategy Paper.

Coordinating the Four Policy Areas: The Importamce of Momitorimg Evaluatiom, amd Dialogure. Because each of the four aforementioned policy areas is conceptually discrete, any description is bound to make the policy prescription sound formulaic. In reality, formulation and coordination of policies across these domains is a dynamic and on-going process. It requires a subtle appreciation on the part of governments as to their role and a deft touch in knowing how and where to be involved or not. It also requires a factual grounding that can only come from careful monitoring, collection of indicators, and evaluation. Here, many developing countries are completely without experience. With the exception of larger, middle-income countries, data are scarce and the amount and quality of dialogue is inadequate. The challenge is to convert the growing interest of politicians in S\&T into opportunities for dialogue on policy and performance, within an integrated and coordinated framework for S\&T in development.

The role of government in the promotion of S\&T is a combination of a number of responsibilities. In addition to the specific areas mentioned earlier in this paper, it involves the inclusion of S\&T-related policies in all levels of education, in industrial policy and the entire legal framework that governs business environments, as well as in any number of specific concerns of "line Ministries" (agriculture, health, energy, environment, transportation, and others). The need for coordination is substantial, as is a 
sound judgment in deciding on the types of action needed across the various sectors. Good science and technology policy is the aggregate of appropriate decisions on frameworks, incentives, direct support, and evaluation/policy analysis across this spectrum.

\section{Lessons from Previous Experience World Bank Experience in Promoting S\&T Capacity}

In a variety of forms, improving S\&T has been a concern of the World Bank for decades. It is worthwhile to extract the lessons of the past when considering directions for future action. However, analyzing previous experience of donors and multi-laterals is difficult because S\&T is a cross-cutting theme. Lessons must be mined from a continuum of sector-specific initiatives in agriculture, health, education, energy, environment, private sector development, and other domains in which S\&T is a key ingredient but not the dominant concern. Nonetheless, analysis of previous experience does lead to several lessons specific to the four policy areas as well as some overall cross-sectoral conclusions.

The World Bank has supported S\&T capacity in (i) education projects; (ii) industrial technology development and other private sector development projects; (iii) agriculture research and extension projects; and, (iv) information and communication technologies projects. Still, apart from Agriculture/Rural Development, and select middle-income countries in East Asia and Latin America, Regions and Networks have not treated S\&T in development in a consistent and systematic way. A number of activities outside of lending operations have been supported by grants from the Development Grant Facility, but again with no systematic attention to S\&T capacity building for the long term.

Specific quantitative analysis of World Bank operational support to S\&T reveals that:

- Between 1980 and 1999 , the World Bank lent $\$ 7.8$ billion to directly support S\&T activities across 590 projects, though fewer than 100 of these contained a significant S\&T capacity building component. Annually, 30 S\&T projects were sponsored, with average lending for S\&T totaling $\$ 390$ million. Five projects a year provided major support for S\&T (greater than $\$ 10$ million) and twenty five projects a year provided minor support for S\&T (less than $\$ 10$ million).

- Most major support for S\&T (outside of agriculture) went to a handful of large, middle-income countries.

- Regionally, East Asia received half of all major S\&T loans during the review period. The next most frequent S\&T borrower, Latin America, took out nearly one-fifth of the loans.

- The DGF provides close to $\$ 100$ million annually for programs that are S\&Trelated.

- The World Bank itself is a funder. of global public goods research for development. In some disciplines, such as development economics, funding and 
publications constitute a significant portion of the input and output for the discipline.

Lessons from the World Bank's diverse experience with S\&T are summarized below. ${ }^{15}$

Lessoms from World Bamk experiemce im thumam resources developmem Three major conclusions from the World Bank's involvement in basic and tertiary education emerge. First, attention to science education has been limited at the primary and secondary levels in both policy dialogue and lending. The support provided has typically prioritized equipment over teacher training, curriculum development, and improving assessment, although somewhat less so recently. Second, sufficient attention has not been given to improving learning outcomes in science. The international assessments of student learning outcomes in science have not been meaningfully incorporated into the World Bank's support for science. By advocating an increase in the number of countries participating in international assessments (e.g., the Trends in International Mathematics and Science Study (TIMSS) and the Program for International Student Assessment (PISA)) the World Bank could encourage monitoring and benchmarking of both student progress and teacher training efforts. The third lesson from the World Bank's involvement with S\&T education, tertiary in particular, is that the overlap between academic training and research and the private sector stands as an important nexus of capacity and use. Tertiary education systems are often the final stage of training for labor market entrants with advanced scientific skills. Creating the right "backward" linkages to the broad reform agenda for tertiary education (e.g., quality assurance, finance, coverage, equity, institutional governance and management, diversification) and the forward linkages to the private sector are both critical steps needed to ensure the successful use of S\&T-educated people for social and economic ends.

Lessons from World Bamk experience in stimulating demand for kmowledge in the private sector The World Bank has fostered a demand for knowledge in the private sector in two ways: by working to improve the overall macroeconomic conditions of its client countries and by directly investing in private sector and industrial technology development activities. With respect to the former, OED evaluations conclude that, on average, adjustment operations have done well in helping countries lay a foundation for accelerating growth, improving macroeconomic conditions, lowering inflation and removing the economic distortions that are damaging for productivity growth. To the extent that such efforts are successful, they will continue to help build a conducive environment in which S\&T can grow and flourish. Lessons from industrial technology development (ITD) show that the success of ITD projects is contingent upon the presence of a well-articulated technology strategy at the national level. Many of the larger, fast growing countries-such as Korea and Singapore - that had such well-crafted policies in place experienced positive S\&T-led growth following subsequent investments in ITD.

15 A more detarled qualitative and qualitative analysis is available in Volume Two, Annex 2. Simularly, lessons from bilateral, NGO, and foundation experience are discussed brefly here and more in depth in Volume Two as well as in Volume Two, Annex 2. 
However, some knowledgeable observers commented that an unwillingness on the part of the World Bank regarding projects that require government interventions for technology development led to a discontinuation of ITD projects in the mid-1990's despite their success.

Also in its review of ITD projects, the OED identified science and technology's disconnect from the private sector as an important obstacle to be overcome. To better foster the necessary linkages and enable ITD's contribution to knowledge development and enhancement, several key actions are suggested, including the need for a core group of specialized staff with interest and expertise in technology lending activities, better dissemination of technology literature within the World Bank to stimulate more discussion on the matter, and at the country level, an emphasis on private sector institutions and their linkages between SMEs and R\&D institutes to narrow the divide existing between the private sector and knowledge-generating institutions.

Lessons learned from fostering partnerships between the private and public sectors serve to reinforce the notion that successful S\&T capacity building requires linkages between these two spheres. Two examples taken from the OECD experience, illustrate the point. The US National Science Foundation helped foster more than a dozen Engineering and Science and Technology Research Centers, by providing ten years of core funding under a decreasing "sunset" clause. Depending upon whether the Centers were engineering focused or science focused, their mandate was centered around providing valuable services to industry, and in the case of the engineering centers, they had to become self-sustaining in order to survive once their public funding was exhausted. The majority of the centers continue to exist today with the potential for future profit-making dependent upon the filing of various patents and the possible commercialization of these technologies. In another example, in the year 2000 , national university professors in Japan were given the right to become board members of private corporations in an effort to enable the transfer of technology to private industry. The legislation also allows researchers who take up a position as a board member to be granted leave without penalizing their retirement allowance. This package of publicprivate partnership-friendly legislation has drastically changed the culture of sharing and exchange now existing between academia and the private sector in Japan [OECD 2000]. Both of these examples underscore the lesson that mutual gains are achievable when the private and public sectors enter into partnership.

Lessons from World Bank experience in public support of S\&T Lessons learned over the course of lending to encourage proper public support of S\&T include the proven importance of creating open, transparent governance and peer review systems at the heart of S\&T systems. These qualities are critical for success in priority setting as well. Other lessons learned include the tendency of the World Bank to over-emphasize physical inputs at the expense of improvements in policy to build public support for S\&T. Major public sector S\&T lending projects from 1980 through the mid-1990s received criticism for such an over-emphasis. Another important lesson learned is the need for sustained engagement and long term commitment, given the timeframes for change in the S\&T sector. 
The World Bank's response to these findings has been, inter alia, to seek to foster excellence through competitive funding mechanisms, using best practice for research management. This has taken the form of project components in higher education reform projects, such as the Quality Improvement Fund (Fundo para el Mejoramiento de la Calidad: FOMEC) in Argentina or the competitive funds in the Chile Higher Education Improvement Project. It has also given rise to the Millennium Science Initiative, an expanding group of projects that seek to improve the quality and efficiency of research systems through an emphasis on excellence (especially as guaranteed by competitively funded peer-reviewed grant allocations), on intense human resources training, and on relevance of research and linkage to the private sector. [See Box 3 for further details about the MSI].

Box 3: The Minlennium Science Initiative: Cain Support to Centers of Escellemce $\mathbb{B e} A$ Catalyst for Reforming Püblic Support of 'S\&T?

In 1998, the Bankibegan programs of support in a small group of countries to promote excellence in research. The initial projects and project components (in Chile, Venezuela, Mexico, and Brazil) for this purpose were grouped together under the Millennium Science Initiative (MSI). The motivation behind creating the MSI was to provide the framework for a highly selective process to make large grants available for grantees to perform scientific work of "international-level quality". The Bank's rationale for funding the MSI extended beyond improving research output alone, however. The MSI was also established as a-means to catalyze efficiency gains and to demonistrate that improved funding processes can vastly improve the performance of $S \& T$ systems as a whole, including the quality of human capital training opportinities and the strength of linkages to the private sector:

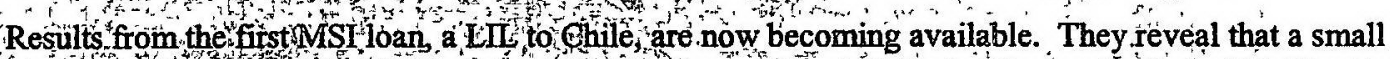
finvestment in quatity $\$ 15$ million in total has leveraged a doubling of the production of $P h$.D.s in: Chile, increasing the figurefriom $40-50 \mathrm{Ph} \mathrm{D}$ s per year in science and engineering to an expected rate of $90-100$ when the first MS S doctoral candiates graduate In addition, quality across the Chilean science system is up sharply and outteach activities to the private sector and the education community have strengthened surpassing expectations. Six patent applications have been filed in two years, some of which have high potential-economic inpact Finally, international linkages have been fortified and the profile of research in Chile has been raised as the entire: Chilean $S \& T$ system has benefited from the changes wrought by the MSI

The ways in which the success realizedin the MSI pilotgroup generalized across the entire Chilean S\&T system aresseveral First, Chile's main funding agency has âdopted the more transparent. allocation processes used by the MSI. Second researchers'use the MSI as-a positive example in dialogue about further -improvements to Chile system Third; Chile has hosted regional S\&T policy meetings under the auspicés of the MSI. Fourth the government has requested a follow-on project that would'seek,to generalize the reforms demonstrated under the MSI LiL

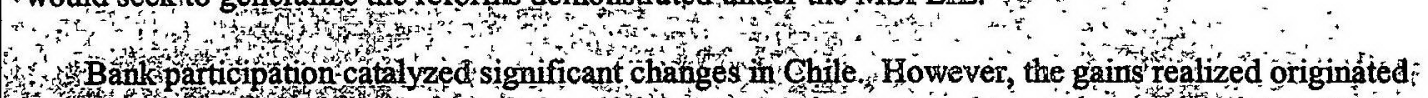

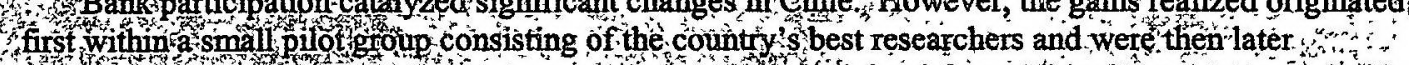

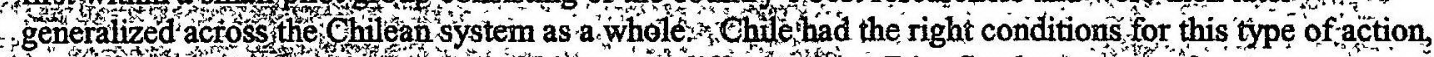
butanother count thy might use the MST i a yery different way. Beneâts do not come from support to Centers of Excellence pers they come from demonstrating that excellence is possible with the right policiess and thenfrom generalizing this demonstration The Bank should continue to use the MSI to initiate action and catalyze reforms where cients seek to improve their under-performing S\& $\hat{T}$, system with explicit links to the higher education systems.

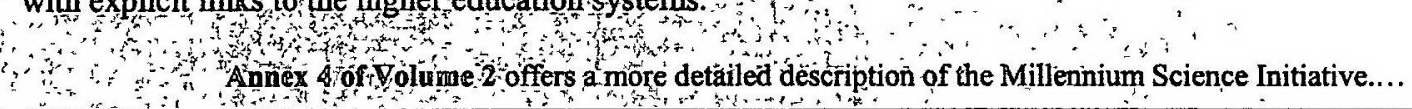


In Agriculture, experience has focused on building capacity in publicly-managed National Agricultural Research Systems (NARS). Despite much notable success, especially in larger middle-income countries, several issues are consistently listed as difficulties or areas in which effectiveness should be increased. First, lack of borrower commitment to sustainable funding limits NARS' success. NARS, like virtually all advanced research systems, accumulate strength and capacity slowly and are by nature extremely vulnerable to even short periods of funding scarcity or excessive fluctuation. Second, management capacity and incentive structures are often weak and inflexible. Lack of capacity in priority setting has been detrimental to relevance and efficiency. Third, more attention needs to be given to human resources development. Even the World Bank's Agricultural Sector Policy Paper published in 1980 called for an increase in the number of trained scientists in the sector (that paper projected an additional 9,000 scientists would be needed in the agricultural sector), yet, until recently, insufficient attention had been given to linking research with human resources training. Fourth, monitoring and evaluation is generally inadequate at the level of research programs and outputs as well as with respect to institutional and policy changes.

According to the analysis of Byerlee and Alex (1998), the incorporation of lessons from past experience in agricultural S\&T has led to changes in lending practices, including a notable shift in priorities after 1993 toward management and policy competence, incentive systems, and accountability. The shift could be described as the adoption of a "quality agenda" that emphasizes: (i) merit and scientific rigor through the use of competitive funding, external reviews, and increased institutional linkages, (ii) sustainability of funding through a variety of mechanisms including public-private interaction, cost-recovery, endowed research foundations, and farmer financing, (iii) more recognition of and support for human resources training, especially as conducted at universities, ${ }^{16}$ (iv) continuing efforts to reform National Agricultural Research Institutes (NARIS) and the policies that affect them, and (v) increasing "knowledge-intensive" agriculture through linkages to basic research and the international knowledge base.

Lessons from World Bank experience in ICT While the World Bank has sponsored several projects and initiatives to establish and/or improve client countries' ICT infrastructure, many of the new World Bank-funded systems are somewhat precariously situated in the client countries. Significant effort is still required to integrate these systems effectively into the societies in which they have been created to make them accessible and useful. Additionally, the World Bank has learned that investments in ICT research and extension must include concomitant investments in human capital as it is necessary to use skilled workers to implement the expansion of ICT programs beyond the initial transition phase. Recent evaluations of the World Bank's ICT work also reveal that IT activities would be more effective if they were integrated more closely with other programs related to the information infrastructure, such as those pertaining to research

\footnotetext{
${ }^{16}$ Page 63 of Byerlee and Alex notes that Bank-supported agriculture R\&D projects should pay more attention to general issues of university quality and improvement, as a means to strengthening NARS. This is a potentially fruitful area of cooperation between staff in the Agriculture and Human Developments Networks.
} 
and private sector development and such initiatives as InfoDev. OED specifically recommends fostering essential experimentation, research and applications that can provide a basis for a more demand-led information infrastructure development program by the World Bank, which would incorporate and build upon the InfoDev program.

In response to several of the aforementioned needs identified by the $O E D$, the World Bank's Global Information and Communication Technologies (GICT) Department now addresses four strategic areas: broadening and deepening sector and institutional reform; increasing access to information infrastructure; supporting ICT human capacity; and, supporting ICT applications. The first area helps create the overall environment for adoption of ICT, while the other three areas share specific goals with the science, technology, education, and productivity concerns that are the subject of this paper. One example of this is the ICT Strategy's emphasis on the need to build human capacity, both for general pedagogy and for sector-specific applications: "the most important use of ICT in education is as a pedagogical tool, when properly integrated into a broader educational program. However, there is also a need for ICT to be used to develop sectorspecific skills and capacity." Other areas, such as fostering public-private partnership, also show significant overlap with and are complementary to the concerns of S\&T in development.

Lessoms from the Development Gramt Facility's Support to S\&T Imitiatives. A review of the funding priorities of the Development Grant Facility (DGF) reinforces the critical role that S\&T issues play in development. Close to two-thirds of total DGF funding goes to S\&T-related programs and priorities. Some grants, such as support for the Global Forum for Health Research are at or near best practice for trying to use S\&T capacity to reduce poverty. Many others fund important specific activities and form strategic partnerships for progress against specific S\&T-related problems in development. However, the weight of S\&T in this important development financing instrument only serves to emphasize the need for a comprehensive strategy for S\&T capacity building in World Bank client countries. Experience to date is not encouraging. The research of the CGIAR has clearly contributed to many breakthroughs in agricultural research, however, while historically the largest DGF grant recipient, it has recognized the modest gains it has made in capacity building in the developing world. Worse, perhaps, collaboration with the CGIAR in the World Bank's operational support to capacity building for agricultural research has been minimal. The most prominent lesson learned from DGF experience is that the knowledge gained from global public goods programs is not being adequately utilized in country programs to the greatest extent possible.

The following table itemizes the DGF programs, by category, that relate to science and technology. The S\&T-related programs constitute almost $\$ 100$ million of the DGF's $\$ 145$ million annual expenditures. 


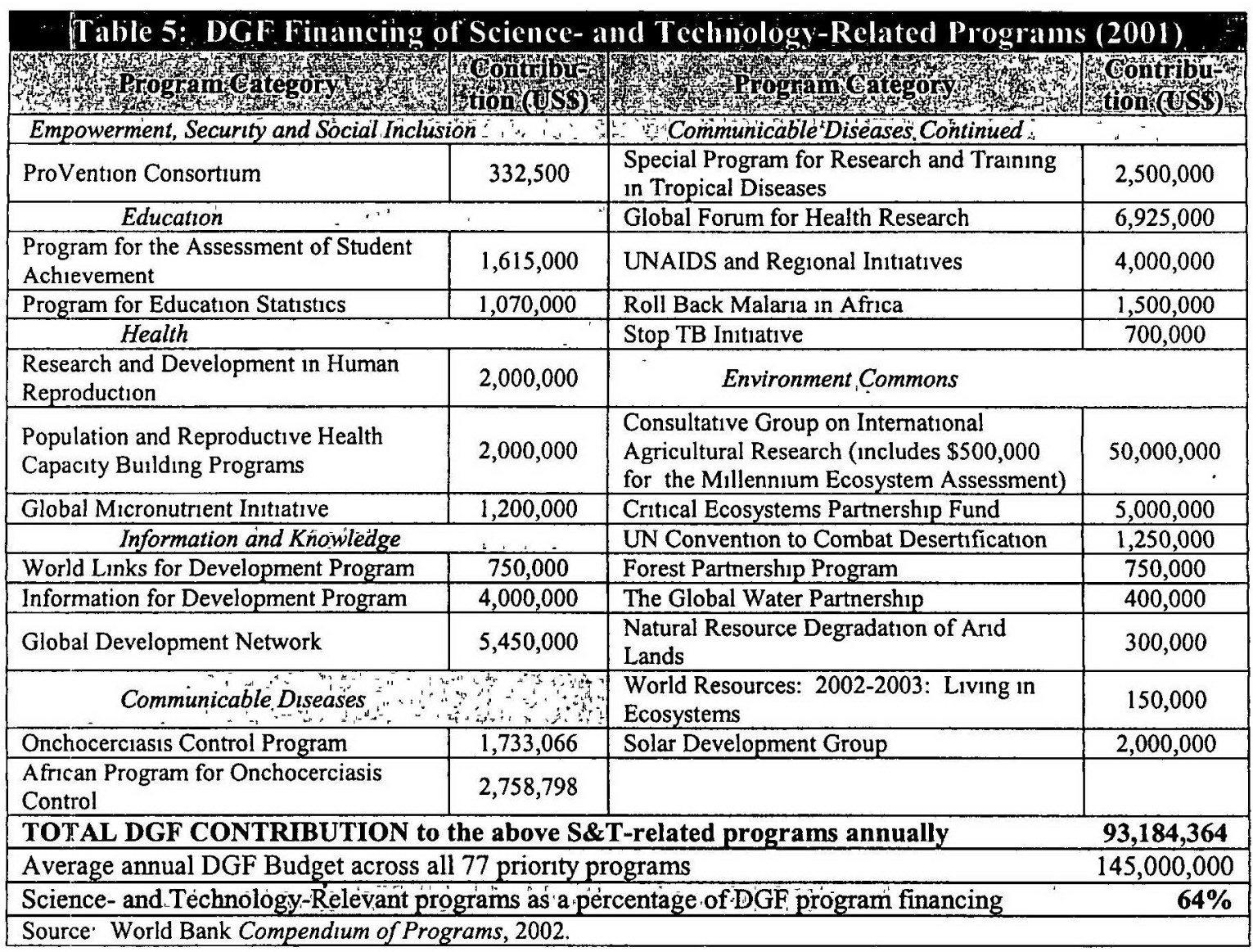

In short, a review of World Bank experience illustrates a history of support for S\&T in which much disparate activity occurred without any coherent framework or longterm goals for improving S\&T capacity in client countries. With the exception of agniculture, the World Bank has also been reactive, and focused on large, middle-income countries whose $S \& T$ infrastructure was already comparatively advanced. While World Bank operational and grant support to S\&T has been effective in some instances, it has generally occurred in vertically isolated "knowledge silos", with little connection to vitally-related activities and areas, across sectors and within them.

Lessons from Bilateral, NGO, and Foundation Experience. A small number of bilateral donors, NGO's and foundations have dedicated programs to improving S\&T capacity over the past few decades. The record is mixed, but cases of success seem to have come from concentrating long-term support on well-defined sub-sectoral goals in smaller countries. This has often been the case for foundations that chose a particular problem, like malaria, and built a program around it. On the negative side, bilateral support has fluctuated enormously, with funding for research being one of the first activities to be cut when budgets are declining. This is especially damaging as continuity of support is vitally important to research and capacity building. In general, only a small sub-group of donors have made systematic attempts to: (i) give prominence and importance to improving S\&T capacity as an essential long-term goal for development; 
(ii) approach S\&T in an integral manner, emphasizing cross-sectoral connections; and (iii) reach out to smaller and poorer countries that have the greatest need and face the greatest challenges in improving their S\&T capacity. Success has been notable, although it has been on a small scale with modest resources. The Nordic bilaterals and the US foundations have the longest histories, but recently the Netherlands, Switzerland, and others have increased their activities for S\&T. These cases of success are a potential source of partnerships for other members of the international S\&T community.

\section{Rethinking the World Bank's Approach to Science and Technology in Development}

The World Bank does not have a specific unit or section bearing central responsibility for promoting S\&T capacity. Although this approach has not prevented the development of some effective initiatives in specific countries or sectors, it may have limited the Bank's ability to develop an integrated and systematic approach toward capacity improvement. To increase its effectiveness, the World Bank is exploring different means: (i) measures to increase awareness of the importance of S\&T and development within the Regions and Networks, (ii) piloting multi-sectoral initiatives, (iii) integrating S\&T concerns into sector strategies and country assistance strategies (CAS's), both of which provide appropriate entry points for issues of science and technology capacity building onto the individual development agendas of client countries; (iv) building the analytical base, and (v) creating partnerships. Any of these courses of action would be facilitated if there were a clearer locus of responsibility and sense of ownership for S\&T capacity. Active synergies will be achieved by the relocation of Science and Technology to the Human Development Network as of July 2002 to more effectively promote the linkages with the Higher Education group. Further synergies within the World Bank might be achieved through the formation of a Thematic Group whose internal members are champions and leaders in S\&T from the Education, Rural, Health, PSD, Energy, Environment and other sectors, as well as from the Regions. Without such a mechanism, it could prove difficult to break with the historical legacy of ad hoc promotion of S\&T.

A multi-sectoral internal Thematic Group is advisable because the steps required to promote S\&T are complex, and essentially involve creation of champions within each Network, along with greater coordination and inter-sectoral cooperation. Creating a program for action across sectors with monitorable indicators will require a great deal of finesse and balance between core responsibilities in the sectors (e.g., Education, Health, Agriculture, etc.) that need to be pursued separately. However, if exploited, synergies among sectors could result in quantum improvements in clients' S\&T capacity. The goals, processes and anticipated outcomes of the creation of the multi-sectoral Science and Technology Thematic Group are described in brief.

\section{The Goals...}

The Thematic Group would lead efforts to raise awareness of the importance of S\&T within each Network and Region by coordinating, sharing knowledge, identifying 
and piloting inter-sectoral initiatives, and leveraging the World Bank's comparative advantage as the institution with the mandate and resources to address the four vital areas of policy that bear on S\&T:

Human Capital Development. Education will continue to be the cornerstone of long-term S\&T capacity building. The main challenge in education is to increase the amount and effectiveness of World Bank attention and support to scientific and technological education at all levels within the framework of general education reform. Specific actions could include:

- Increasing the emphasis on science education in basic and secondary education lending. This would also include encouragement and operational support for wider participation of developing countries in teacher training, curriculum development, physical investments (where appropriate), and assessment of outcomes. A starting point could be increased participation of World Bank clients in international assessments of achievement in mathematics and science.

- Including science and technology as part of the renewed and expanded emphasis on tertiary education. To participate more fully in the knowledge economy, more countries are seeking to strengthen the core knowledge institutions that constitute their tertiary education systems. The World Bank has increased and broadened its portfolio of tertiary education activities, placing emphasis on meeting the challenges of expanded access with quality and cost effectiveness. In some cases, tertiary education reform has also included attention to S\&T issues, but this is predominately the case for large middle-income countries. The challenge is to make S\&T a part of tertiary education reform for a broader spectrum of clients.

Stimulation of Demand for Technology from the Private Sector. The World Bank should explore ways to include concern for S\&T as part of its important work of improving investment climates and increasing the knowledge content of economic activity. While many issues on this agenda must be carried forward simultaneously, more attention can be given to those key pressure points that induce greater use of technology in the private sector and the removal of obstacles to knowledge sharing and S\&T diffusion. Among the means for achieving this are the following:

- Renew emphasis on the creation of linkages between firms and knowledge institutions. World Bank lending operations should continue to explore innovative means to reduce barriers and information problems that stifle greater use of knowledge in production. Stimulation of contact between university and industry, or appropriate support for the formation of clusters of knowledge-based industries are among the diverse mechanisms that can be part of a series of measures designed to increase knowledge flows in firms.

- Reform enabling environments for better use of knowledge. Intellectual property rights administration, as well as taxation, credit policy, and 
competition policy reform should routinely be included in World Bank efforts to improve the investment climate in all client countries.

Stremgthening the Public Role im S\&T. The nature of the World Bank's support for improving the public role in $S \& T$ is likely to vary greatly according to country circumstances. Nonetheless, interventions should revolve around:

- Priority setting and evaluation. As it expands to work with a greater range of client countries, the World Bank should provide support and technical assistance to help smaller, poorer countries plan and set priorities in S\&T. This could involve the development of evaluation and diagnosis techniques that consider where success is most likely and how limited S\&T resources can be effectively concentrated on the most socially and economically useful investments.

- Promoting transparency, objectivity, and selectivity and international best practices in $S \& T$ funding. One of the most effective ways the World Bank can promote long-term, sustainable improvements to national research systems is through promoting the adoption of international best practice in funding with transparent, objective peer-review selection processes. A principal means for doing this could be the expansion of the Millennium Science Initiative beyond its successful beginning in Latin America [See Volume Two Annex 4].

- The government as a consumer of knowledge. Not only is there a role for the public sector to help fund and support knowledge-creation, but there is also a role for the government as a user of knowledge. In creating S\&T-relevant policies, the public sector necessitates access to the scientific knowledge necessary to understand the likely outcomes of policy decisions, thus, there is a role for the World Bank to assist in building capacity to utilize scientific knowledge and to serve as a potential clearinghouse for some types of S\&Trelated information needed by public sector decision-makers.

Imcreasing Access to ICTs. As the core work of the Global ICT group expands, opportunities should be sought to make the S\&T infrastructure more available to potentially innovative firms, knowledge institutions, national research systems, and other stakeholders. The main instrument of the World Bank will continue to be policy and regulatory reform, given its potential system-wide impact. Additionally, the World Bank should continue to focus less on the R\&D aspects of new ICTs and focus its efforts primarily on widening distribution and usage across regions and countries. As called for in the recent ICT Strategy, future action will also need to prioritize support for ICT human capacity.

\section{The Process...}

The process through which the Thematic Group should pursue these goals would include building a community of practice within the World Bank that unites stakeholders and champions whose work depends on strengthened capacity in various aspects of S\&T. 
This process would stimulate greater attention to S\&T issues in each Network, coordination of key policies, and the piloting of cross-sectoral operations that take a more integrated approach to improving S\&T capacity in areas that are key to development, such as:

$>$ Combining improvements in policy frameworks for the private sector and the tertiary education sector. Examples of such industry-academia linkages might include specific actions in medical education, agronomy, natural resources management, or other areas.

$>$ Building on knowledge assessments with coordinated lending efforts across sectors (e.g., in Private Sector Development or Human Development). Client demand is high for analytical products that demonstrate the role of knowledge, especially scientific and technological knowledge, in new strategies for growth. The World Bank has responded with a number of technical assistance and non-lending services through the WBI's Knowledge for Development program. These should be followed by specific lending services in the relevant sectors.

$>$ Emphasizing a development-oriented approach to improving science and technology in larger middle-income countries. This involves encouraging the harmonization of the four policy areas detailed extensively in this document.

$>$ Developing regional $S \& T$-based interventions around specific development problems. This might be aimed to provide groups of smaller, poorer states with a focused set of strategies to address specific development problems (in health, agriculture, the environment or other areas) around which they could concentrate efforts to improve their capacity, performance, and policies in the S\&T sector. ${ }^{17}$

Periodically the Thematic Group would report to the Board on the progress made in each of the aforementioned areas.

Building the Analytical Base, Promoting Global Public Goods for S\&T and Fostering Partnerships. Along with increased operational emphasis on S\&T, key areas for new analytical work (AAA) and participation in international fora and activities that will strengthen the knowledge base for S\&T in development should be identified and pursued. This would include more work on critical issues such as gathering and extending the best current knowledge on the phenomenon of migration of scientists, technicians, and other highly skilled individuals from the developing world. ${ }^{18}$ The outcomes of this and other AAA work might provide the basis for greater awareness and advocacy on key development issues.

Another important part of an adequate analytical base for S\&T in development would entail expansion of the World Bank's participation in international scientific assessments, such as the Millennium Ecosystem Assessment (currently funded in part by

17 Annex 1 of Volume 2 provides more in-depth coverage of some of the regional unterventions specific to the Africa region.

18 See Volume Two, p.39. 
the DGF) and the work of the Inter-governmental Panel on Climate Change (IPCC). These scientific assessments, which involve hundreds of experts from all over the world from all stakeholder groups, address issues that are at the heart of the World Bank's work on environment and development. The World Bank should remain involved, both through funding (as is the case with the Millennium Ecosystem Assessment) and through the participation of World Bank staff, when the issues under consideration, like climate change or the conditions of fragile ecosystems, have a clear link and relevance to poverty and development. Other potential areas for involvement include the role of S\&T in agricultural productivity and food safety and new technologies that relate to costeffective delivery of health care services in the developing world.

At the same time, the Thematic Group could explore ways in which the World Bank could play a potentially large and beneficial role in the area of public regulation of science and technology. Whether in public health, bio-safety, agricultural productivity, or related trade and commerce issues, the need for effective public regulatory capacity for S\&T-related issues is growing daily, and the capacity of the majority of developing country governments is not keeping pace. The World Bank, using its staff and its partnerships, as well as the Global Distance Learning Network and other WBI outreach products, could facilitate training and capacity building around specific regulatory issues in S\&T. These services, if designed correctly, are likely to be in high demand from client governments, which struggle more than ever with new issues in bio-safety and related areas. The World Bank could serve as well as an entry point for complementary policy dialogue and operational activities built around the goal of long-term improvement of S\&T capacity.

Finally, on a global level, the Thematic Group could take the lead in facilitating new partnerships and deepening existing ones. One part of such an effort might be on the stimulation of the public-private partnerships that can make development-relevant knowledge available and usable. In the new international context of S\&T, private companies now generate an increasing percentage of the new knowledge and technologies available. By keeping the World Bank involved with both public and private entities, poverty issues could be kept on the international research agenda as opposed to being marginalized in the for-profit sector. While it is true that most of the new knowledge generated pertains to rich country markets, much of what is developed is still highly relevant to the problems facing the developing world. The marginal cost of making the new knowledge and research available can be negligible, especially if channels exist to bridge the gaps between producers and users. Private companies have expressed willingness to share such data when it will be used for public purposes, however, often the channels for distribution and outreach are not there in the private sector. The World Bank should be actively engaged in building partnerships with the private sector to ensure the maximum use and distribution of knowledge and research for the global public good, particularly given the trend toward increasing private ownership of key S\&T knowledge.

International partnerships between the World Bank and other multilateral organizations, bilaterals, NGOs and various entities engaged in science and technology 
for development should also be fostered. While strategic partners already strengthen a number of the working groups within the World Bank, including the International Labor Organization, the World Health Organization, the World Wildlife Fund and many others, an even greater number of partners with an explicit concern for S\&T in development would be sought to strengthen the Bank's work in S\&T. The World Bank's ability to catalyze partnerships in S\&T would extend to specific organizations, including: bilateral aid agencies concerned with S\&T for development (e.g., SAREC, ENRECA, DGIS and NORAD); national scientific foundations, academies, and international science organizations (e.g., the Inter-Academy Council, the Third World Academy of Sciences and the International Council of Scientific Unions,); specialized multilateral organizations (e.g., the OECD and the World Trade Organization); and NGOs and other multilaterals concerned with science (e.g., the Bill and Melinda Gates Foundation, the Rockefeller Foundation, UNESCO, and the World Health Organization). (see Volume Two pages 86-87 and Volume Two Annex Two for a fuller discussion of partnerships).

\section{Anticipated Outcomes...}

If the World Bank pursues a more systematic approach to S\&T, woven into the regular programs of Networks and Regions through the workings of a well-organized Thematic Group, a decade from now, as we approach the established deadline for reaching the Millennium Development Goals, the World Bank could find itself in a situation in which:

- The responsibility for S\&T issues in development is established with a professional Thematic Group that coordinates the growing number of S\&T-related activities in the World Bank's work, maximizing the institution's impact.

- Education projects routinely include adequate, culturally appropriate science education components that raise student learning outcomes.

- Middle-income countries have increased the quantity, quality, and relevance of their scientific and technological output in areas that make direct contributions to social and economic goals.

- Low-income countries have targeted human resources development programs that channel talent toward the sectors with the greatest technical needs and that hold the highest opportunity for economic growth and development.

- Infrastructure for research and employment in the sciences has improved throughout the developing world, and subsequently pressure to emigrate has decreased.

- The critical mass of researchers working on development-related problems has increased.

- Access to and transfer of knowledge between producers, wherever they may be, and end-users in firms and public entities, has grown substantially.

- Connections among innovative firms and talented researchers has grown worldwide.

- The critical mass of skilled personnel that developing countries need to implement the Millennium Development Goals is available. 
Under such circumstances, the World Bank would help to promote a much fuller contribution of science and technology to the development agenda. 


\author{
Appendix One: \\ Sustainably Implementing and Monitoring the \\ Millennium Development Goals Will Require Improved S\&T \\ Capacity in Client Countries
}

\title{
Millennium Development Goals and the S\&T: Inputs Necessary for: their Attainment

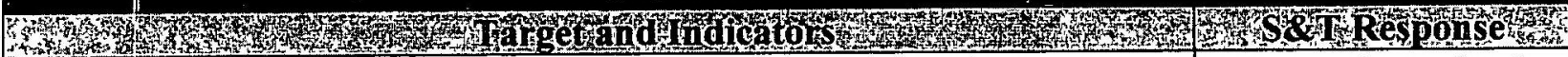

Halve between 1990 and 2015, the proportion of people who suffer from hunger

- Prevalence of under-weight children (Under five years of age)

- Proportion of population below minimum level of dietary energy consumption research and enhanced food security regimes

Improved access to basic education, including science and math

Ensure that by 2015 , children everywhere, boys and girls alike, will be able to complete a full course of primary schooling

- Net enrollment in primary education

- Proportion of pupils starting grade 1 who reach grade 5

- Illiteracy rate of 15-24-year-olds education that is built around appropriate

curricula and delivered by well-trained teachers

Reduce by two thirds, between 1990 and 2015, the under-five mortality ratio

- Under-five mortality rate

- Infant mortality rate

- Proportion of 1-year-old children immunized against measles

Reduce by three quarters, between 1990 and 2015, the maternal mortality ratio

- Maternal mortality ratio

- Proportion of births attended by skilled health personnel

Have halted by 2015 and begun to reverse the spread of HIV/AIDS

- HIV prevalence among 15- to 24-year-old pregnant women

- Contraceptive prevalence rate

- Number of children orphaned by HIV/AIDS

Have halted by 2015 and begun to reverse the incidence of malaria and other major diseases

- Prevalence and death rates associated with malaria

- Proportion of population in malaria risk areas using the effective malaria prevention and treatment measures

- Incidence of tuberculosis (per 100,000 people)

- Proportion of tuberculosis cases detected and cured under directly observed treatment short course

Integrate the principles of sustainable development into country policies and programmes and reverse the losses of environmental resources

- Proportion of land area covered by forest

- Land area protected to maintain biological diversity

- GDP per unit of energy use (a proxy for energy efficiency)

- Carbon dioxide emissions (per capita)

Halve by 2015 the proportion of people without sustainable access to safe drinking water

- Proportion of population with sustainable access to an improved water source By 2020 to have achieved a significant improvement in the lives of at least 100 million slum dwellers

- Proportion of people with access to improved sanitation

Contunued research and development into needed vaccines and treatments and improved distribution of available vaccines and treatments for these diseases
Continued research and development of

alternative energy sources and enhanced land-use systems including ground water management techniques, sustainable forestry techniques and improved sanitation systems 


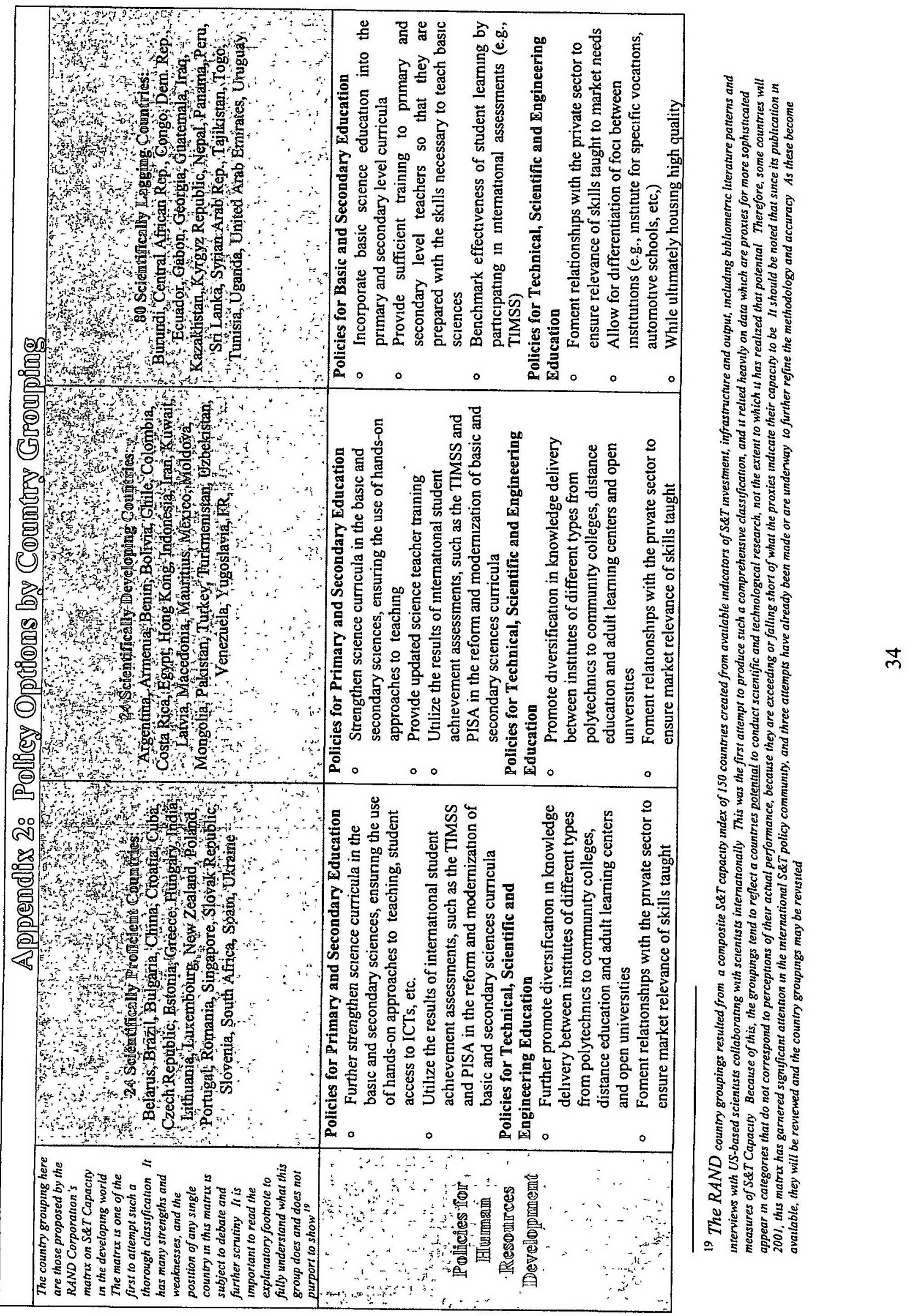




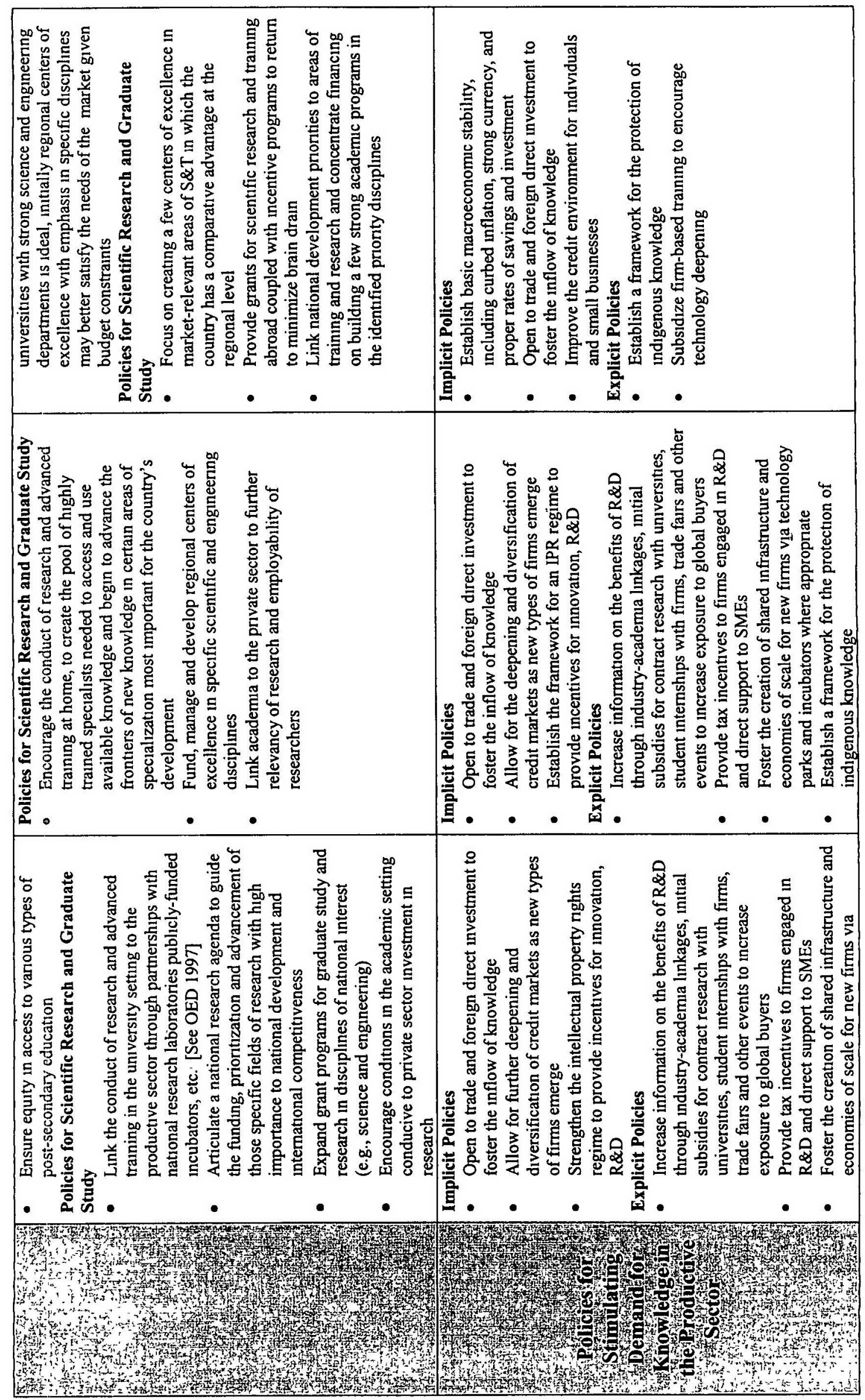




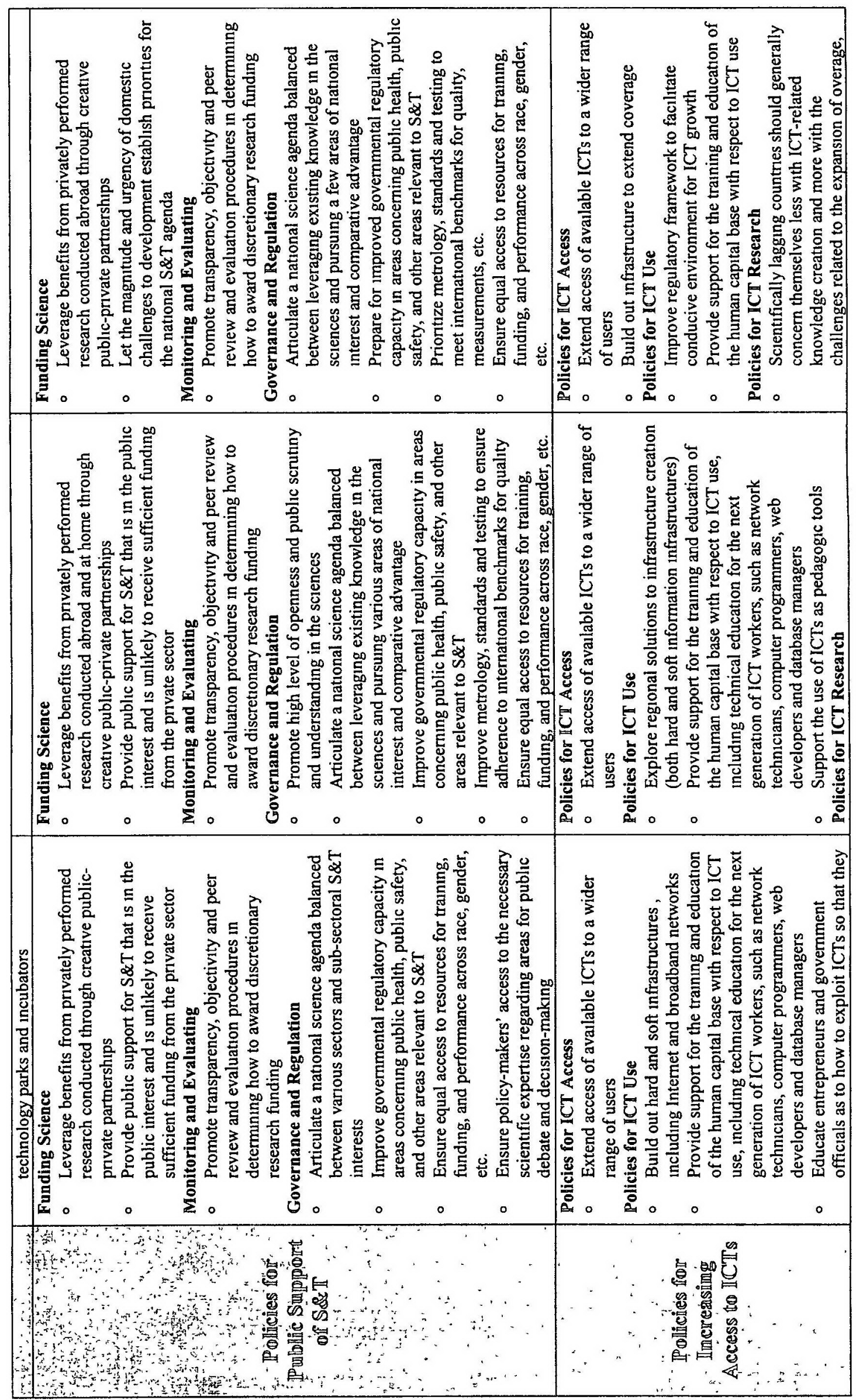




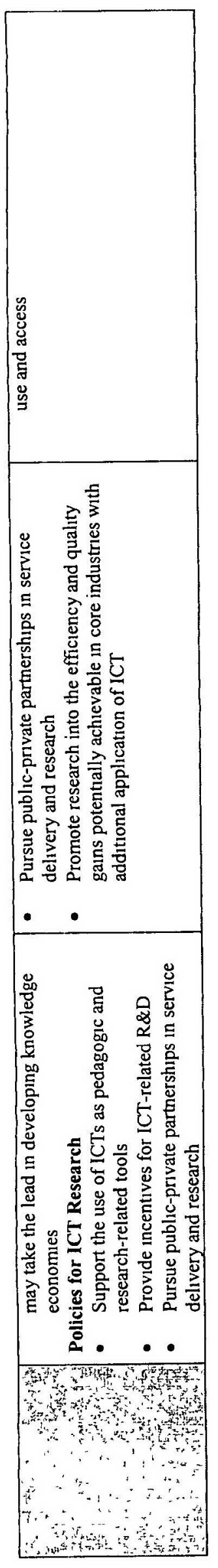

n 
Appendix Three:

Reviewers and Consultants

John Gibbons

Former Science Advisor to President Clinton, and MSI Panel Chair

United States

Dr. Edward Ayensu

President of the Pan African Union for Science and Technology

Ghana

Dr. Simon Schwartzman

Former Director of the Brazilian Bureau of the Census

Brazil

Dr. R. K. Pachuari

Director of the Tata Energy Research Institute

India

Dr. Enric Banda

Secretary General of the European Science Foundation

Spain

Dr. Peter Tindemans

Director for Science and Technology Policy in the Netherlands Ministry of Education Netherlands

Dr. Bruce Alberts

President of the National Academy of Sciences

United States

Mohamed Hassen

Executive Director, Third World Academy of Sciences

Italy

Dr. Hameed Ahmad Khan

Executive Director, Commission on Science and Technology for Sustainable Development in the South Pakistan

Dr. Ibrahim Othman

Director General, Atomic Energy Commission of Syria

Syria

Dr. Jacques Gaillard

Deputy Director, International Foundation for Science

Sweden

Mu Shik Jhon

President, The Association of Academies of Sciences in Asia

Korea

Larry Kohler

Executive Director, International Council for Science

Dr. Juan Carlos Navarro

Chief ad interim, Education Unit Inter.-American Development Bank

United States 


\section{Dr. Michael Hoffmann}

Director General, Federal Ministry for Economic Cooperation and Development Germany

\section{Ali Al-Shamlan}

Director General, Kuwait Foundation for the Advancement of Scrences

Kuwait

\section{Lydia Makhubu}

President, Third World Organization of Women in Science, Vice Chancellor University of Swaziland Swaziland

\section{Bernard Petit}

Director, DG Development, European Commission

Belgıım

\section{Dr. Thomas Rosswall}

Durector, International Foundation for Science

Sweden

\section{N. R. Rao}

President, Third World Academy of Sciences and Honorary President, Jawaharlal Nehru Centre for Advanced Scientific Research

India

\section{Walter Alhassan}

Direcior General, Council for Scientific and Industrial Research

Ghana

\section{Goverdhan Mehta}

President, Indian National Science Academy

India

\section{Yongxiang Lu}

President, Chinese Academy of Sciences

China

\section{Yves Quere}

Fore1gn Secretary, Academe des Sciences, Delegation aux Relations Internationales France

Souleymane Niang

President, Academie des Sciences et Techniques

Senegal

\section{Thamas Odhiambo}

Honorary President, African Academy of Sciences

Kenya

\section{Dr. Reinder Van Duinen}

Presıdent, European Science Foundation and Netherlands Organization for Science Research (NWO) Nether lands

Rafael Vicuña

Vice-President Chilean Academy of Sciences

Chile 


\section{Dr. Pedro Aymonino}

Director National Academy of Exact, Physical and Natural Sciences

Argentina

G. O.P. Obassi

Secretary General, World Meteorological Society

Switzerland

\section{Gerald Lalor}

Durector-General, International Centre for Environmental and Nuclear Sciences

Jamaica

Dorairajan Balasubramanian

Director of Research, L.V. Prasad Eye Institute

India

\section{Dr. Abdul Omar}

Charrman, CPTM, Science Advisor, Prime Minister's Department

Malaysia

\section{Dr. Abdul Zakri}

Director, Institute of Advanced Studies, United Nations University

Japan

John Grayzel

Director, Office of Development Programs, USAID

United States

Hoan Vu. Tuyen

President, Vietnam Unıon of Science and Technology Associations

Vietnam

\section{Laura Kansikas}

Director, Department for Development Cooperation, Ministry of Foreign Affairs

Finland

Dr. Howard Mnoore

Chief, Science Publications Unit UNESCO

Dr. Phillip Griffiths

Director, Institute for Advanced Study

United States

\section{Hon. Att-Ur-Rahman}

Minister, Ministry of Science and Technology

Pakistan

Jacob Palis

Director, Instituto de Matemática Pura e Aplicada

Brazıl

Elisabeth Beton Delegue

Directrice de la Cooperation Scientifique, Universitaire et de la Rechereche, Ministere des Affaries Etrangeres

France 


\section{F. I. B. Kayanja}

Vice Chancellor Mbarara University of Science and Technology

Uganda

\section{Victor Ngu}

President Cameroon Academy of Sciences

Cameroon

\section{Wataru Iwamoto}

Deputy Director General, National Science Museum, Special Inspector, Elementary and Secondary

Education Bureau

Japan

\section{Miguel Virasoro}

Durector, Vaduz Salam International Centre for Theoretical Physics

Italy

\section{Mohan Munasinghe}

Chairman, Munasinghe Institute for Development

Srı Lanka

\section{Muha mmad Akhtar}

Emertus Professor, University of Southampton

United Kıngdom

Francisco Tilak-Viegas

Principal Scientıfic Officer, DG Research, European Comısión

Belgium

\section{Michael Oborne}

Deputy Director, DSTI of OECD

Dr. Daniel Maselli

Swiss Agency for Development and Cooperation

Switzerland

\section{Dr. Berit Olsson}

Department for Research Cooperation SAREC

Sweden

Dr. Eric Thulstrup

Department of Life Sciences and Chemistry, Roskilde University

Denmark

\section{Attia Ashour}

Department of Mathematics, Cairo University

Egypt

\section{Dr. Mohamed Shamsher Ali}

Department of Physics, University of Dhaka

Bangladesh

Dr. Nacisco Matos

Carnegie Corporation of New York

United States 
Elisabeth Beton-Delegue

Minıstere des Affaries Etrangeres

France

Etim M. Essien

Department of Haematology and Immunology

Nigeria

Fidel Castro Diaz-Balart

Member Cuban Academy of Sciences

Cuba

Susan Thompson

Office of Agriculture and Food Security

United States

Claude Freud

Center for International Cooperation in Agronomic Research for Development

France

Dr. Jon-Andri Lys

Swiss Commission for Research Partnerships with Developing Countries

Switzerland

Brent Herbert-Copley

International Development Research Center

Canada

Dr. Hans Hurni

Centre for Development and Environment, University of Berne

Switzerland

Caroline Wagner

Science and Technology Policy Institute, RAND

United States

Cecilia Scharp

Swiss Agency for International Development, Department for Research Cooperation of Sida (SAREC)

Sweden

Andrew Bennett

Department for International Development

England

Gilles Saint-Martin

DRIC-Ministere de la Recherche/Ministere de l'Education Natıonale

France

Hanns Sylvester

German Academuc Exchange Service

Germany

Jacques Gaillard

International Foundation for Science 
Jean-Michel Chasseriaux

Institute de Rechereche pour le Developpement

France

John Grayzel

United States Agency for International Development

United States

Jon-Andri Lys

Swiss Commission for Research Partnershıps with Developing Countries

Switzerland

Klaus Winkel

Royal Danısh Ministry of Foreıgn Affaurs

Denmark

Leen Boer

Research and Communication Division, Dutch Ministry of Foreign Affairs

Netherlands

Lill-A.nn Bjaarstad Medina

Research Advisor, Norwegian Agency for Development Cooperation

Norway

Najia Kbir-Ariguib

Institut National de Recherche Scientifque et Technique

Tunisia

Peter M. Msolla

Deputy V1ce-Chancellor, Sokoine University of Agriculture

Tanzania

Philippe Barré

Ministry of Foreign Affairs

France

Prof. Abed Peerally

Casa Blanca

Mauritius

Prof. Peimbert

Instituto de Astronoma

Mexico

Renée van Kessel

Research Council for the Netherlands' Special Unit for Cooperation with Developing Countires (WOTRO)

Netherlands

Driss Ben Sari

University Mohammad V., Mohammadia School of Engineers

Morocco

Dung T. Le

CMI-Universite de Provence

France 
Reza Mansouri

Department of Physics, Sharif University of Technology

Iran

Caroline Wagner

RAND

United States

Robert-Jan Scheer

DGDEV Research and Development, European Commission

Belgium

Richard Carey

OECD

Mario Cervantes

OECD

Brian Hammond

OECD

Mustafa EI-Tayeb

UNESCO

Tony Marjoram

UNESCO

Paul Fallon

UNESCO

Robert-Jan Scheer

European Commission

John Campbell

InterAcademy Council

Sachiko Ishizaka

International Counctl for Science

Hameed Khan

COMSATS

Enric Banda

European Science Foundation 


\section{Appendix Four:}

\section{Bibliography}

\section{Agriculture and Biotechnology}

- Alex, A. 1997. USAID and Agricultural Research, Review of USAID Support for Agricultural Research-1952-1996. Washington, DC: World Bank.

- Alston, J. et al. 2000. A Meta-Analysis of Rates for Return to Agricultural R\&D, Ex Pede Herculem? Research Report 113. Washington, DC: International Food Policy Research Institute.

- Anderson, J. and D. Dalrymple. 1999. The World Bank, the Grant Program and the CGIAR, a Retrospective Review. Washington, DC: World Bank Operations Evaluation Department.

- Byerlee, D. and G. Alex. 1998. Strengthening National Agricultural Research Systems. Washington, DC: World Bank.

- Byerlee, D. and K. Fischer. 2000. Accessing Modern Science: Policy and Institutional Options for Agricultural Biotechnology in Developing Countries.

- CGIAR. 1998. Third System Review of the Consultative Group on International Agricultural Research (CGIAR). Washington, DC: CGIAR.

- CGIAR. Reducing Poverty Through Cutting-Edge Science. Summary of Proceedings from CGIAR International Centers Week, October 25-29, 1999. Washington, DC: World Bank.

- Doyle, J. and G. Persley. 1996. Enabling the Safe Use of Biotechnology, Principles and Practice. Washington, DC: World Bank.

- Lele et al. 2000. Intellectual Property Rights in Agriculture, The World Bank's Role in Assisting Borrower and Member Countries. Washington, DC: World Bank.

- Margulis, S. and T. Vegleseter. 1999. Environmental Capacity Building: A review of the World Bank's Portfolio. Washington, DC: World Bank.

- McKevitt, K. 1998. Cooperating to Enrich Earth's Capacity: The Agricultural Biotechnology for Sustainable Productivity Project. Lansing, Michigan: ABSP Project.

- Paarlberg, R. 2000. Governing the GM Crop Revolution, Policy Choices for Developing Countries. Washington, DC: International Food Policy Research Institute.

- Pardey, P. and N. Beintema. 2001. Slow Magic, Agricultural R\&D a Century After Mendel. Washington, DC: International Food Policy Research Institute. .

- Pardey, P. et al. 1996. Hidden Harvest: U.S. Benefits from International Research Ard. Washington, DC: International Food Policy Research Institute.

- Pehu, E. at al. 2001. Science and Technology in Securing Food in the $21^{\text {st }}$ CenturyChallenges, Issues and Options. Washington, DC: Rural Development Department, World Bank.

- Persley, G and P. George. 1996. Banana Improvement, Research Challenges and Opportunities. Washington, DC: World Bank. 
- Persley, G and P. George. 1999. Banana Breeding and Biotechnology, Commodity Advances Through Banana Improvement project Research, 1994-1998. Washington, DC: World Bank.

- Persley, G. and C. Brenner. March 2000. Executive Summary: Agricultural Biotechnology, Poverty Reduction and Food Security in Asia. Report commissioned by the Asian Development Bank, Australian Centre for International Agricultural Research, and the Australian Agency for International Development.

- Rosegrant, M. et al. 2001. Global Food Projections to 2020, Emerging Trends and Alternative Futures. Washington, DC: International Food Policy Research Institute.

- Serageldin, I. and W. Collins. 1999. Biotechnology and Biosafety. Washington, DC: World Bank.

\section{Health}

- Geneva, Switzerland: The Council on Health Research and Development.

- Global Forum for Health Research. 2000. The 10/90 Report on Health Research, 2000. Switzerland: Global Forum for Health Research, World Health Organization.

- International Organizing Committee. 2001. Report of the International Conference on Health Research for Development, Bangkok, 0-13 October 2000. Switzerland: International Conference on Health Research for Development.

- The Council on Health Research and Development. 2000. Lessons in Research to Action and Policy, Case Studies from Seven Countries. COHRED issues paper. Geneva, Switzerland: The Council on Health Research and Development.

- The Council on Health Research and Development. 2000. The ENHR Handbook.

- The report describes the progress made by the partners in the Global Forum in the past Global Forum for Health Research. 2001. Monitoring Financial Flows for Health Research. Switzerland: Global Forum for Health Research, World Health Organization.

- World Health Organization. 1997. A Research Policy Agenda for Science and Technology to Support Global Health Development. Geneva, Switzerland: World Health Organization, Advisory Committee on Health Research.

- World Health Organization. 1997. The Advisory Committee on Health Research, An Overview. Geneva, Switzerland: World Health Organization.

\section{NGOs and Multilaterals}

- Gaillard, J. and A. Tullberg. 2001. Questionnaire Survey of African Scientists, IFS Grantees and INCO Beneficiaries. Report No. 2. Stockholm, Sweden: International Foundation for Science.

- International Foundation for Science. 1999. Annual Report, 1999. Stockholm, Sweden: International Foundation for Science.

- Special Unit for Technical Cooperation Among Developing Countries, et al. Sharing Innovative Experiences, Examples of Successful Initiatives in Science and Technology in the South Volume 1. New York, New York: Special Unit for Technical Cooperation Among Developing Countries. 
- The Global Alliance for Diversifying the Science and Engineering Workforce. Linking Science and Technology to Women's Needs. Washington, DC: American Association for the Advancement of Science.

- Third World Network of Scientific Organizations. 1998. Profiles of Institutions for Scientific Exchange and Training in the South. Triest, Italy: Third World Academy of Sciences.

\section{Technology Transfer and Evaluation}

- Boh, B. September 1994. Scientific Information and Literature. ESP Discussion Paper Series, 43. Washington, DC: The World Bank.

- Fitzsimmons, S. et al. June 1996. An Evaluation of the NSF Science and Technology Centers (STC) Program. Volume I: Summary. Cambridge, MA: Center for Science and Technology Policy Studies.

- Martin, M. et al. December 2000. TIMSS 1999 International Science Report. Chestnut Hill, MA: The International Study Center, Boston College.

- Mullis, I. et al. December 2000. TIMSS 1999 International Mathematics Report. Chestnut Hill, MA: The International Study Center, Boston College.

- OECD. 1997. The Evaluation of Scientific Research, Selected Experiences. Paris, France: Organization for Economic Co-operation and Development.

- Parker, L. December 1997. The Engineering Research Centers Program: An Assessment of Benefits and Outcomes. Arlington, VA: National Science Foundation.

- Payson, S. March 1999. National Patterns of R\&D Resources: 1998. SRS Special Report. Arlington, VA: National Science Foundation.

- Ware, S. May 1999. Science and Environment Education Views from Developing Countries. Washington, DC: The World Bank.

\section{Energy, ICT, the Environment}

- Lvovsky, K. et al. 2000. Environmental Costs of Fossil Fuels, A Rapid Assessment Method With Application to Six Cities. Environment Department Paper, No. 78. Washington, DC: The World Bank.

- Mendelsohn, R. 2001. The Impact of Climate Change on the Poor: market Impacts in Africa, Asia and Latin America. New Haven, CT: Yale School of Forestry and Environmental Studies.

- Panel on International Cooperation in Energy Research, Development, Demonstration and Deployment. June 1999. Powerful Partnerships, The Federal Role in International Cooperation in Energy Innovation. Washington, DC: Executive Office of the President of the United States.

- Schware, R., et al. 2001. Information and Communication Technologies (ICT) Sector Strategy Paper. Washington, DC: The World Bank.

- Talero, E. P. Gaudette. 1996. Harnessing Information for Development, A Proposal for a World Bank Group Strategy. World Bank Discussion Papers 313. Washington, DC: The World Bank.

- United Nations Development Programme. 2000. Energy and the Challenge of Sustainability. New York, NY: United Nations. 
- Watson, R. et al. 1998. Protecting Our Planet Securing Our Future. Nairobi, Kenya: United Nations Environmental Programme.

- World Bank. 2000. Toward an Environmental Strategy for the World Bank Group. Washington, DC: The World Bank.

- World Bank. July 27, 1999. Fuel for Thought, Environmental Strategy for the Energy Sector. Washington, DC: The World Bank.

- World Energy Council. 2000. Energy for Tomorrow's World Acting Now! WEC Statement 2000. London, UK: World Energy Council.

Knowledge Economy, Economies of Research and Development and Thowledge Assessments

- Birdsall, N. and C. Rhee. November 1993. Does Research and Development Contribute to Economic Growth in Developing Countries. Policy Research Working Paper 1221. Washington, DC: The World Bank.

- Dahlman, C. 1994. "Technology Strategy in East Asian Developing Economies." Journal of Asian Economies. Vol. 5, No. 4.

- Dollar, D. and A. Kraay. March 2001. Trade, Growth and Poverty. Washington, DC: The World Bank.

- International Monetary Fund. September 25, 2000. Poverty Reduction and Global Public Goods, Issues for the World Bank in Supporting Global Collective Action. Washington, DC: International Monetary Fund.

- Lall, S. June 2000. Skills, Competitiveness and Policy in Developing Countries. Working Paper No. 46. Washington, DC: The World Bank.

- Mansfield, E. January 1994. Economic Returns from Investments in Research and Training. Human Resources Development and Operations Policy Paper, 19. Washington, DC: The World Bank.

- National Research Council. 1996. Prospectus for National Knowledge Assessment. Washington, DC: National Academy Press.

- OECD. 1996. The Knowledge-Based Economy. Paris, France: Organization for Economic Cooperation and Development.

- OECD. 1997. National Innovation Systems. Paris, France: Organization for Economic Cooperation and Development.

- OECD. 2000. A New Economy? The Changing Role of Innovation and Information Technology in Growth. Paris, France: Organization for Economic Cooperation and Development.

- Popper, S. and C. Wagner. January 2001. New Foundations for Growth: The U.S. Innovation System Today and Tomorrow. Santa Monica, CA: RAND.

- Rausch, L. 1995. Asia's New High-Tech Competitors. Arlington, VA: National Science Foundation.

- Report of the Expert Panel on Canada's Role in International Science and Technology. 2000. Reaching Out, Canada, International Science and Technology and the Knowledge-Based Economy. Ottawa, Ontario: Advisory Council on Science and Technology.

- Roessner, J.D. et al 1992. "National Capacities to Absorb and Institutionalize External Science and Technology," Technology Analysis and Strategic Management. 
Vol. 4,

No. 2.

- Romer, P. March 19, 2000. Should the Government Subsidize Supply or Demand in the Market for Scientists and Engineers. Palo Alto, CA: Stanford University.

- Sachs, J. June 24, 2000. "A New Map of the World," The Economist. London, UK: The Economist Newspaper Group Ltd.

- Stephan, P. September 1996. "The Economics of Science," Journal of Economic Literature. Vol. 34.

\section{Industry-University Links and Intellectual Property Rights}

- Braga, C. et al. 1998. Intellectual Property Rights and Economic Development. Washington, DC: The World Bank infoDev.

- Cohen, J. October 21, 1999. Managing Intellectual Property-Challenges and Responses for Agricultural Research Institutes. Paper prepared for the conference, "Ensuring Food Security, Protecting the Environment, and Reducing Poverty in Developing Countries: Can Biotechnology Help?" October 21-22, 1999.

Washington, DC: The World Bank.

- Luthria, M. and B. Fikkert. June 1999. Patent Protection in a Developing Country: Of What Value? Estimates for India.. PSD Occasional Paper No. 34. Washington, DC: The World Bank.

- Luthria, M. July 1999. Patent Protection for Whom? An Intersectoral Comparison. PSD Occasional Paper No. 35. Washington, DC: The World Bank.

- Maraboto, J. 1997. Managing University-Industry Relations, The Case of the Centre for Technological Innovation at UNAM. Paris, France: International Institute for Educational Planning.

- Martin, M. 2000. Managing University-Industry Relations, A Study of Institutional Practices from 12 Different Countries. Paris, France: International Institute for Educational Planning.

- Ostrovski, C. November 1995. University-Industry Collaboration-R\&D and Technology Transfer. Toronto, Canada: Technology Partners Inc.

- Parker, L. September 1992. Industry-University Collaboration in Developed and Developing Countries. PHREE Background Paper 92/64. Washington, DC: The World Bank.

- Popper, S. et al. 1998. New Forces at Work, Industry Views Critical Technologies. Santa Monica, CA: RAND.

- Primo Braga, C. et al. 2000. Intellectual Property Rights and Economic Development. World Bank Discussion Paper No. 412. Washington, DC: The World Bank.

- Resetar, S. 1999. Technology Forces at Work, Profiles of Environmental Research and Development at DuPont, Intel, Monsanto and Xerox. Santa Monica, CA: RAND.

- Smarzynska, B. 2000. Technological Leadership and the Choice of Entry Mode by Foreign Investors. Washington, DC: The World Bank.

- Smarzynska, B. August 2000. Composition of Foreign Direct Investment and Protection of Intellectual Property Rights: Evidence from Transition Economies. Washington, DC: The World Bank. 
- Wagner, C. and A. Yezril. 1999. Global Science and Technology Information, A New Spin on Access. Santa Monica, CA: RAND.

- Wagner, C. et al. 2001. International Cooperation in Research and Development, An Update to an Inventory of U.S. Government Spending. Santa Monica, CA: RAND.

- World Bank. 2000. 2000 World Bank Atlas. Washington, DC: The World Bank.

\section{World Bank Previous Experience}

- Muskin, J. March 1992. World Bank Lending for Science and Technology. PHREE Background Paper 92/51R. Washington, DC: The World Bank.

- The World Bank. 1982. Technology and Science in World Bank Operations. Washington, DC: The World Bank.

- The World Bank. 2002. World Bank Support for Global and Regional Initiatives Under the Development Grant Facility, Compendium of Programs.

- Weiss, C. January 18, 1985. "The World Bank's Support for Science and Technology." Science. Vol. 227. Washington, DC: American Association for the Advancement of Science.

- World Bank Operations Evaluation Department. 2001. Global Public Policies and Programs, Implications for Financing and Evaluation. Washington, DC: World Bank Operations Evaluation Department.

\section{Countries and Regional Case Studies}

- Appenzeller, T. February 1995. "Points of Light in Latin America." Science. Vol. 267.

- Caribbean Academy of Sciences. 1998. Furthering Co-Operation in Science and Technology for Caribbean Development. Trinidad and Tobago: Caribbean Academy of Sciences.

- Dahlman, C. and J. Aubert. 2001. China and the Knowledge Economy, Seizing the $21^{\text {st }}$ Century, Overview. Washington, DC: The World Bank Institute.

- De Ferranti, D. et al. September 2001. From Natural Resources to the Knowledge Economy, Trade and Job Quality. Washington, DC: The World Bank.

- Macilwain, C. et al. April 1999. "Science in Latin America." Nature. Washington, DC: Nature Press.

- The World Bank. June 29, 2000. Republic of Korea, Transition to a KnowledgeBased Economy. Washington, DC: The World Bank.

- Weiss, C. 1993. "Scientific and Technological Responses to Structural Adjustment."Technology in Society. Vol. 15. 281-299.

- Zymelman, M. 1993. Assessing Engineering Education in Sub-Saharan Africa. World Bank Technical Paper No. 197. Washington, DC: The World Bank.

\section{Education}

- Bork, A. March 20, 2001. Better Learning Worldwide Through Tutorial ComputerBased Units and Scientific Literacy. Irvine, CA: University of California at Irvine.

- Bybee R. and P. Legro. Developing and Implementing Standards to Improve Science Education: Perspective on the U.S. Experience. Concept Paper Prepared for the World Bank Human Development Department. Washington, DC: The World Bank. 
- Lopez, R. et al. December 1998. Addressing the Education Puzzle, The Distribution of Education and Economic Reform. Policy Research Working Paper 2031. Washington, DC: The World Bank.

- National Science Foundation. 2000. Graduate Education Reform in Europe, Asia, and the Americas and International Mobility of Scientists and Engineers: Proceedings of the NSF Workshop. Arlington, VA: National Science Foundation.

- Pritchett, L. November 11,2000. An Economist's Midnight Thoughts on Education: The Puzzle of Government Production. Boston, MA: Kennedy School of Government.

- Teasdale, G. 1998. "Local and Global Knowledge in Higher Education: A Search for Complementarity in the Asia-Pacific Region." International Journal of Educational Development. Vol. 18, No. 6. 501-511.

- The World Bank. 2000. Higher Education in Developing Countries, Peril and Promise. Washington, DC: The World Bank.

\section{Science and Technology Policy and Previous Strategies}

- Betz, F. 1987. Managing Technology, Competing Through New Ventures, Innovation and Corporate Research. Englewood Cliffs, NJ: Prentice-Hall.

- Bezanson, K. and G. Oldham. June 2000. Issues and Options Concerning a European Foundation for Research and Development. Brighton, UK: Institute of Development Studies.

- Carrington, W. and E. Detragiache. June 1999. "How Extensive is Brain Drain." Finance and Development. Washington, DC: The International Monetary Fund.

- Committee on Science, Engineering and Public Policy. 1999. Capitalizing on Investments in Science and Technology. Washington, DC: National Academy Press.

- Eisemon, T. and L. Hom-Nielsen. April 1995. Developing Capacity for Research and Advanced Scientific Training: Lessons from World Bank Experience. ESP Discussion Paper No. 62. Washington, DC: The World Bank.

- Gaillard, A. and J. Gaillard. September 1998. "The International Circulation of Scientists and Technologists." Science Communication. Vol. 20, No. 1. 106-115.

- Gaillard, J. 2001. "Building Research Capacity in the Developing World: Issues and Prospects. The Experience of the International Foundation for Science (IFS)." Enhancing Research Capacity in the Developing and Transition Countries. Berne, Switzerland: KFPE.

- Gaillard, J. June 15, 1995. Donor Models for Strengthening Research Capacity Building in Developing Countries. Upsala, Sweden: International Conference on Donor Support to Development Oriented Research in Basic Sciences.

- Gaillard, J. and E. Thulstrup. 1994. Research Capacity Building Through NorthSouth Cooperation: A Possible Strategy for World Bank Projects. ESP Discussion Paper Series No. 42. Washington, DC: The World Bank.

- Gibbs, W. August 1995. "Lost Science in the Third World." Scientific American.

- Hongqi, Z. et al. January 2000. An Assessment of Twenty Years of Research Collaboration, Between China and The International Development Research Centre. Canada: The International Development Research Centre. 
- Institute of Development Studies. June 2000. Selected Review of International Institute Supporting Development Research, Issues and Options Study. Brighton, UK: Institute of Development Studies.

- Kamenetzky, M. et al. 1984. Choice and Management of Technology in Developing Countries, a Program for Decision-Makers. Washington, DC: The World Bank.

- Lall, S. 1995. Science and Technology in the New Global Environment: Implications for Developing Countries. New York, NY: United Nations.

- Mayorga, R. January 1997. Closing the Gap. Washington, DC: The World Bank.

- Miller, R. and M. Cote. July/August 1995. "Growing the Next Silicon Valley." Harvard Business Review. Boston, MA: Harvard Business School.

- National Science and Technology Council. April 2000. Ensuring a Strong U.S. Scientific Technical and Engineering Workforce in the $21^{\text {st }}$ Century. Washington, DC: The White House.

- Stiglitz, J. January 27, 1999. Public Policy for a Knowledge Economy. Washington, DC: The World Bank.

- Tansey, G. February 1999. Trade, Intellectual Property, Food and Biodiversity. Geneva, Switzerland: Quaker United Nations Office.

- Thulstrup, E. March 1994. Scientific Research for Development. Human Resources Development Operations Policy Paper, No. 25. Washington, DC: The World Bank. 


\section{Policy Research Working Paper Series}

Title

\author{
WPS2996 Bank Competıtıon, Fınancıng \\ Obstacles, and Access to Credit \\ WPS2997 Financial and Legal Institutions \\ and Firm Size
}

WPS2998 Does Micro-Credit Empower Women?
Evidence from Bangladesh

\begin{abstract}
WPS2999 Explaınıng Liberalızatıon Commitments in Financial Services Trade

WPS3000 Internatıonal Ciımate Regıme beyond 2012 Are Quota Allocations Rules Robust to Uncertaınty?

WPS3001 An Introduction to Financial and Economic Modeling for Utility Regulators
\end{abstract}

Author

Date

Contact

for paper

Thorsten Beck

Asl1 Demırguç-Kunt

Vojıslav Maksımovic

Thorsten Beck

Aslı Demırguç-Kunt

Vojıslav Maksimovic

Mark M Pitt

Shahıdur R Khandker

Jennifer Cartwright

Philipp Harms

Aaditya Mattoo

Ludger Schuknecht

Franck Lecocq

Renaud Crassous

WPS3002 Information-Based Instruments for Improved Urban Management

WPS3003 The Investment Clımate and the Firm Firm-Level Evidence from

\section{Antonio Estache} Martín Rodríguez Pardına José María Rodríguez

Germán Sember

Uwe Derchmann

Somik V Lall

Ajay Surı

Pragya Rajorıa

Mary Hallward-Driemeier

Scott Wallsten

Lıxın Colın Xu

WPS3004 Institutions, Trade, and Growth Revisitıng the Evidence

David Dollar

Aart Kraay

Varun Gaurı

WPS3005 Vouchers for Basic Education in Developıng Countries A PrıncıpalAgent Perspective

Ayesha Vawda

WPS3006 Soclal Rights and Economics· Claıms Varun Gauri to Health Care and Education in Developing Countries

WPS3007 The Impact of Urban Spatıal Structure Antonıo M Bento on Travel Demand in the United States

Maureen L Cropper Ahmed Mushfıq Mobarak Katja Vınha

WPS3008 Technology, Computers, and Wages: Chrıs N Sakellarıou Evidence from a Developıng Economy Harry A Patrınos

WPS3009 Agriculture in the Doha Agenda

Patrıck Messerlın

WPS3010 Vulnerability in Consumption,

Edmundo Murrugarra Education, and health Evidence from José Signoret Moldova during the Russian Crisis

\section{March 2003}

March 2003

March 2003

March 2003

March 2003

March 2003

March 2003

March 2003

March 2003

March 2003

March 2003

March 2003

P Sintım-Aboagye

March 2003

April 2003

April 2003 37644

A Bonfield 31248

$\mathrm{H}$ Sladovich 37698

H Sladovich 37698

$\checkmark$ Soukhanov

35721

K Labrie

K Labrie

P Kokıla 31001

P Flewitt 32724

$\mathrm{V}$ Soukhanov 35721

G Chenet-Smith 36370

Y D'Souza
31449

$N$ Vergara

30432

P Flewitt 32724

E Murrugarra 34452 


\section{Policy Research Working Paper Series}

Title

WPS3011 Renegotiation of Concession Contracts in Latın America WPS3012 Just-In-Case Inventories: A Cross-
Country AnalysIS

WPS3013 Land Sales and Rental Markets in Transition: Evidence from Rural Vietnam

WPS3014 Evaluation of Financial Liberalızation. A General Equilibrium Model with Constrained Occupation Choice

WPS3015 Off and Running? Technology, Trade, and the Risıng Demand for Skilled Workers in Latın Amerıca

WPS3016 Partısan Politıcs and Intergovernmental Transfers in India

WPS3017 Why is Unemployment so High in Bulgarı?

WPS3018 Integratıng the Least Developed Countries into the World Trading System: The Current Impact of EU Preferences under Everythıng but Arms

WPS3019 Foreign AId, Conditıonality, and Ghost Thilak Ranaweera of the Financing Gap: A Forgotten Aspect of the Aid Debate

WPS3020 Consumption, Health, Gender, and Poverty

WPS3021 Institutional Arrangements for Public Debt Management

WPS3022 Sendıng Farmers Back to School: The Impact of Farmer Field Schools in Indonesia

WPS3023 Productivity Growth and Product Variety: Gains from Imitation and Education

WPS3024 R\&D and Development

WPS3025 Trade Structure and Growth
Author

J. LuIs Guasch Jean-Jacques Laffont Stéphane Straub

J. Luis Guasch Joseph Kogan

Klaus Deınınger

Songqing Jin

Xavier Gıné Robert M. Townsend

Carolina Sánchez-Páramo Norbert Schady

Stuti Khemani

Jan Rutkowski

Paul Brenton

Anne Case

Angus Deaton

Elizabeth Currie

Jean-Jacques Dethier

Eriko Togo

Gershon Feder

Rinku Murgai

Jaime B. Quizon

Douglas M. Addison

Daniel Lederman

Willıam F. Maloney

Daniel Lederman

Willam F. Maloney
Date

April 2003

April 2003

April 2003

Contact for paper

April 2003

April 2003

J. Troncoso 37826

April 2003

M. Fernandez 33766

April 2003

K Labrie 31001

H Sladovich 37698

H Sladovich 37698

April 2003

J Rutkowski 84569

L. Tabada 36896

April 2003

P. Rathan Raj 33705

D. Ballantyne 87198

M. Rosenquist 82602

April 2003

P. Kokıla 33716

April 2003

D. Addison 31188

April 2003

P. Soto 37892

April 2003

P. Soto 37892 